Federal Reserve Bank of New York
Staff Reports

\title{
Rollover Risk as Market Discipline: A Two-Sided Inefficiency
}

\author{
Thomas M. Eisenbach
}

Staff Report No. 597

February 2013

Revised October 2016

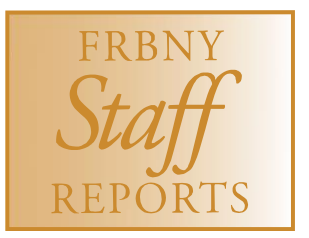

This paper presents preliminary findings and is being distributed to economists and other interested readers solely to stimulate discussion and elicit comments. The views expressed in this paper are those of the author and do not necessarily reflect the position of the Federal Reserve Bank of New York or the Federal Reserve System. Any errors or omissions are the responsibility of the author. 


\title{
Rollover Risk as Market Discipline: A Two-Sided Inefficiency
}

Thomas M. Eisenbach

Federal Reserve Bank of New York Staff Reports, no. 597

February 2013; revised October 2016

JEL classification: C73, D53, G01, G21, G24, G32

\begin{abstract}
Why does the market discipline that financial intermediaries face seem too weak during booms and too strong during crises? This paper shows in a general equilibrium setting that rollover risk as a disciplining device is effective only if all intermediaries face purely idiosyncratic risk. However, if assets are correlated, a two-sided inefficiency arises: Good aggregate states have intermediaries taking excessive risks, while bad aggregate states suffer from costly fire sales. The driving force behind this inefficiency is an amplifying feedback loop between asset values and market discipline. In equilibrium, financial intermediaries inefficiently amplify both positive and negative aggregate shocks.
\end{abstract}

Key words: rollover risk, market discipline, fire sales, global games

Eisenbach: Federal Reserve Bank of New York (e-mail: thomas.eisenbach@ny.frb.org). The author is grateful to his advisors, Markus Brunnermeier and Stephen Morris, for their guidance. For helpful comments and discussion, the author also thanks Sushant Acharya, George-Marios Angeletos, Magdalena Berger, Dong Beom Choi, Paolo Colla, Douglas Diamond, Jakub Jurek, Charles Kahn, Todd Keister, Jia Li, Xuewen Liu, Konstantin Milbradt, Benjamin Moll, Martin Oehmke, Justinas Pelenis, Wolfgang Pesendorfer, José Scheinkman, Martin Schmalz, Felipe Schwartzman, Hyun Song Shin, David Sraer, Jeremy Stein, Wei Xiong, Adam Zawadowski, and Sergey Zhuk. Any errors are those of the author. The views expressed in this paper are those of the author and do not necessarily reflect the position of the Federal Reserve Bank of New York or the Federal Reserve System. 


\section{Introduction}

The use of short-term debt by financial intermediaries and the resulting rollover risk were prominent features of the financial crisis of 2007-09. Besides providing liquidity services, the maturity mismatch of intermediaries' balance sheets can be viewed as playing a disciplining role to address the bankers' incentive problems (Calomiris and Kahn, 1991; Diamond and Rajan, 2001). Historically, this role was associated with the depositors of commercial banks but in today's more market-based system of financial intermediation the role can be extended to banks' (and shadow banks') creditors in wholesale funding markets (Adrian and Shin, 2010).

The experience leading up to and during the crisis, however, calls into question the effectiveness of short-term debt as a disciplining device: On the one hand, the increasing reliance on short-term debt in the years before the crisis went hand-inhand with exceedingly risky activities on and off financial institutions' balance sheets (Admati, DeMarzo, Hellwig, and Pfleiderer, 2013). On the other hand, the run on short-term funding at the heart of the recent crisis was indiscriminate and effectively delivered a "collective punishment," shutting down the issuers of securities backed not only by real estate loans but also by entirely unrelated assets such as student loans (Gorton and Metrick, 2012). As Carey, Kashyap, Rajan, and Stulz (2012) point out:

"Market discipline" is a commonly suggested method of promoting stability and efficiency. Many studies find evidence that it pushes prices and quantities in the "right" direction in the cross section. [...] Casual observation suggests that market discipline is "too weak" during credit booms and asset price bubbles, and "too strong" after crashes. True? If so, why? Is there a role for policy action?

In this paper, I address these questions in a general equilibrium model of financial intermediaries (or "banks") choosing how much to rely on short-term debt. The maturity mismatch between assets and liabilities generates rollover risk, which I model using global game techniques. Bankers use the rollover risk as a disciplining device since they face a basic risk-shifting problem. The model shows that this form of market discipline can only be effective - and achieve the first-best allocation - if banks face purely idiosyncratic risk. When, in addition, banks face aggregate risk from correlated assets, a two-sided inefficiency arises: Good aggregate states have banks taking excessive risks 
in projects with negative net present value; bad aggregate states suffer from fire sales as projects with positive net present value are liquidated.

More specifically, I assume a setting where banks invest in long-term projects funded by a mix of short-term and long-term debt. In an interim period, each bank receives news about the expected return on its investment at which point the project can be abandoned and its assets sold to a secondary sector. This setup implies that banks receiving sufficiently bad news about their project should liquidate it while banks with sufficiently good news should continue. However, since the bank's equity holders don't share in the liquidation proceeds, they have an incentive to continue projects with negative net present value, i.e. an expected return lower than their liquidation value.

Issuing short-term debt that can be withdrawn after news about the bank's project arrives in the interim period provides a potential remedy for the banker's risk-shifting problem. If sufficiently many short-term creditors withdraw their funding, the bank is unable to repay it's remaining creditors and fails, forcing liquidation of its assets. This generates strategic complementarities among the short-term creditors - the classic coordination problem at the heart of panic-based bank runs (Diamond and Dybvig, 1983) - raising the issue of multiple equilibria. I therefore use the global game approach which eliminates common knowledge among players to resolve the multiplicity of equilibria (Carlsson and van Damme, 1993b; Morris and Shin, 2003). However, in contrast to a conventional partial equilibrium analysis of creditor coordination at an individual bank, my paper tackles a general equilibrium problem, which adds significant technical complications given that equilibrium payoffs depend on equilibrium strategies. In particular, the endogeneity of liquidation values in general equilibrium implies that there is strategic interaction of creditors both within and across banks. This requires a generalization of the usual approach, e.g. in Morris and Shin (2003), that can be useful also in other general equilibrium analyses with strategic complementarities.

Given the global game equilibrium at the interim stage, a bank choosing the maturity structure of its debt ex ante effectively controls in which states of the world it is forced to liquidate ex post. In the absence of aggregate risk, I show that this allows the bank to commit to the efficient liquidation policy, effectively tying its hands and resolving the incentive problem.

However, with aggregate risk due to correlation in the banks' projects, a wedge appears between what is ex post efficient and what is achievable when choosing a 
debt-maturity structure ex ante: On the one hand, in a bad aggregate state, where liquidation values are low, the hurdle return for a project to be viable is lower than in a good aggregate state. On the other hand, when liquidation values are low, each creditor is more concerned about the other creditors withdrawing their funding and therefore less willing to roll over than when liquidation values are high. Therefore, the bank will be less stable and more likely to suffer a run by its short-term creditors in bad aggregate states. With a symmetric problem in good aggregate states, a bank faces a trade-off in choosing its reliance on short-term debt: higher rollover risk reduces excessive risk taking in good aggregate states but increases harmful liquidation in bad aggregate states.

General-equilibrium feedback loops between asset liquidation values and market discipline are the driving force behind this financial-sector-induced procyclicality. With correlation between banks' assets, good aggregate states imply good news about the average bank's assets, increasing bank stability. Creditors worry less about others withdrawing, which weakens market discipline. Since not many banks are forced to liquidate assets, asset values are inflated. This increases bank stability further, feeding back into even weaker market discipline. In contrast, bad aggregate states imply bad news about the average bank's assets, reducing bank stability and making creditors more likely to run. Market discipline is strengthened, forcing many banks to liquidate and depressing asset values. This reduces bank stability further, feeding back into even stronger market discipline. The result of these feedback loops is inefficiently weak market disciplinewith inflated asset values and excessive risk taking - in good states and inefficiently strong market discipline - with depressed asset values and excessive liquidation - in bad states.

The model has implications for regulation and policy interventions. Any policy to reduce reliance on short-term debt, while decreasing the fire-sale inefficiency of downturns, would at the same time increase the risk-taking inefficiency of booms. I show that which of the two welfare effects dominates is not obvious and depends on how many bank assets are affected on the margin and on how sensitive asset values are to liquidation, both across aggregate states.

There is, however, clear scope to improve welfare by affecting the state contingency of market discipline. Ideally, banks' exposure to rollover risk should be tailored to each aggregate state to reduce the inefficiencies at the macro-level of the banking sector 
while preserving the disciplining effect at the micro-level of the individual bank. I show that this could be achieved by replacing some of a banks long-term debt with "financial crisis bonds," a form of event-linked bonds whose interest and principal is written off in case of a trigger event - here a crisis state. Partially replacing regular long-term debt by such crisis bonds raises the bank's debt burden in good aggregate states and at the same time reduces its debt burden in bad aggregate states. This increases exposure to rollover risk in good states while decreasing it in bad states, allowing the bank more control over the liquidation policies it implements and restoring the efficiency result of the case without aggregate risk. Alternatively, the state contingency can originate in central bank interventions with broadly targeted support of asset values during times of stress. This relaxes the trade-off banks face between the fire-sale inefficiency and the risk-taking inefficiency, improving overall welfare. Finally, regulation can try to address the correlation between banks' assets that is at the heart of the inefficiency. More diversification of risks across banks would result in less volatility in asset values and less amplification, thereby reducing the inefficiency.

Related Literature: The events of the recent crisis have generated a large body of literature. ${ }^{1}$ The realization of rollover risk as the dry-up of short-term funding is well documented for the asset-backed commercial paper market (Kacperczyk and Schnabl, 2010; Covitz, Liang, and Suarez, 2013) and the market for repurchase agreements (Gorton and Metrick, 2012; Copeland, Martin, and Walker, 2014). This has inspired theoretical work on the mechanisms underlying rollover risk in market-based funding, highlighting the fragility of the collateral assets' debt capacity (Acharya, Gale, and Yorulmazer, 2011) or separating the contributions of liquidity concerns and solvency concerns (Morris and Shin, 2010). The main difference in my paper is that I take an ex-ante perspective in a general equilibrium setting and highlight inefficient risk taking in good states as the mirror image of inefficient fire sales in bad states.

The role of short-term debt as a disciplining device has been discussed in a literature going back to Calomiris and Kahn (1991). ${ }^{2}$ This literature commonly takes a partialequilibrium view where the benefit of a disciplining effect has to be traded off against

\footnotetext{
${ }^{1}$ For overviews of the events see, e.g. Brunnermeier (2009) and Gorton (2008).

${ }^{2}$ See, e.g. Rajan (1992), Leland and Toft (1996) and Diamond and Rajan (2001). For a recent approach with interesting dynamic effects see Cheng and Milbradt (2012). The literature on control rights has similar themes, e.g. Aghion and Bolton (1989).
} 
the cost of inefficient liquidation. In contrast, I do not assume exogenous liquidation costs or discounts relative to fundamental value, e.g. due to uniformly inferior secondbest users (Shleifer and Vishny, 1992) or limited cash in the market (Allen and Gale, 1994). In my paper, liquidation is similar to Kiyotaki and Moore (1997) and therefore not necessarily inefficient. In particular, my paper has an efficient benchmark outcome if only idiosyncratic risk is present. The novel inefficiency then arises because of the inability of the disciplining mechanism to deal with two sources of risk. Hence market discipline gets things right in the cross section but leads to mirror-image inefficiencies in good and bad aggregate states due to amplification effects in general equilibrium.

Related from a technical point of view are several papers that also use global game techniques to analyze the coordination problem among creditors, notably Morris and Shin (2004), Rochet and Vives (2004) and Goldstein and Pauzner (2005). ${ }^{3}$ In my paper, the global game is not as much front and center but rather used as a modeling device. Under weak assumptions, the global game has a unique equilibrium and this equilibrium has continuous comparative statics. This allows me to study the ex-ante stage where the maturity structure is chosen optimally, taking into account the effect on the globalgame equilibrium at a later stage. Finally, since the global game itself is restricted to a single time period, the complications in dynamic global games pointed out by Angeletos, Hellwig, and Pavan (2007) do not arise.

In the following, Section 2 lays out the model and discusses the important features. Section 3 considers the situation of an individual bank, deriving the endogenous rollover risk in Subsection 3.1 and comparing the case without aggregate risk in Subsection 3.2 to the case with aggregate risk in Subsection 3.3. Section 4 analyzes the general equilibrium with many banks and highlights the amplification leading to the two-sided inefficiency. Finally, Section 5 discusses the policy implications and Section 6 concludes.

\footnotetext{
${ }^{3}$ The global game approach originates with Carlsson and van Damme (1993a,b). Kurlat (2010) studies the trade-off between disciplining and inefficient liquidation using a global game setting. In a related model not using a global game setup, He and Xiong (2012) study the inter-temporal coordination problem among creditors with different maturity dates. For other recent work using global games to study strategic interaction of creditors see, e.g. Szkup (2013) or Ahnert (2015).
} 


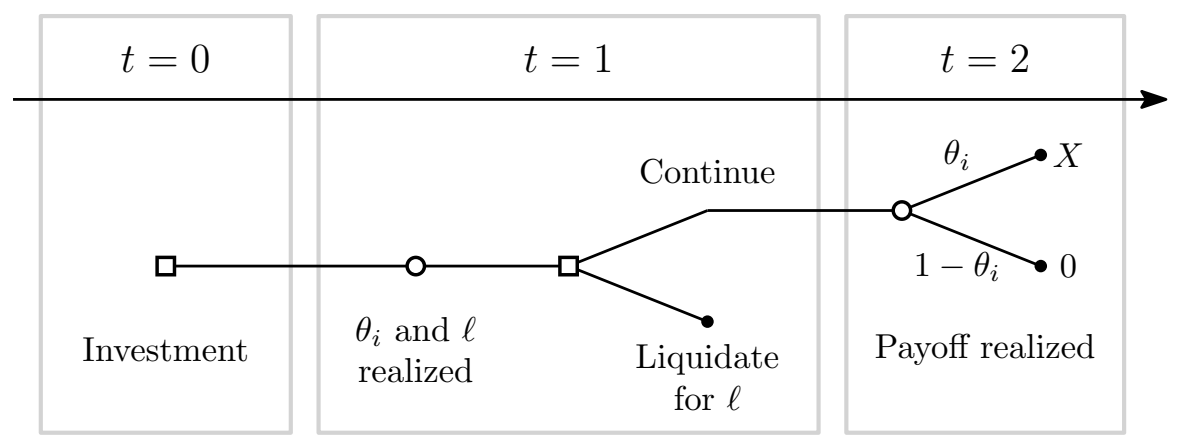

Figure 1: Project time-line for bank $i$

\section{Model Setup}

Time is discrete and there are three periods $t=0,1,2$. There is a continuum of banks $i \in[0,1]$, each with the opportunity to invest in a project. Each bank $i$ has a continuum of creditors $j \in[0,1]$. There is no overlap between the creditors of banks $i$ and $i^{\prime}$; a creditor $j$ of bank $i$ is uniquely identified as $j i$. All agents are risk neutral with a discount rate of zero.

Project: Each bank $i$ 's project requires an investment of 1 in the initial period $t=0$ and has a random payoff in the final period $t=2$ given by $X>1$ with probability $\theta_{i}$ and 0 otherwise. In the interim period $t=1$, the project can still be abandoned and any fraction of its assets can be sold off to alternative uses at an endogenous liquidation value of $\ell$. At the time of investment in $t=0$, there is uncertainty about both the project's expected payoff $\theta_{i} X$ as well as the liquidation value $\ell$, which is not resolved until additional information becomes available in the interim period $t=1$. The structure of a bank $i$ 's project and its time-line is illustrated in Figure 1.

Importantly, in $t=1$ the liquidation value $\ell$ is not directly linked to the expected payoff $\theta_{i} X$ of bank $i$ 's project. It helps to think of the project as a loan to a borrower against collateral such as real estate or machines. Over time, the bank learns more about its borrower's repayment probability $\theta_{i}$ and can foreclose the loan and sell the collateral. Since the value of the collateral is not directly linked to the idiosyncratic repayment probability of the borrower, liquidation is not inherently inefficient. Instead, efficiency requires that a project be abandoned and that its assets be liquidated whenever the 
expected payoff $\theta_{i} X$ turns out to be less than the liquidation value $\ell$ and vice versa:

$$
\begin{aligned}
& \theta_{i} X \leq \ell \quad \Rightarrow \quad \text { abandon } \\
& \theta_{i} X>\ell \quad \Rightarrow \quad \text { continue }
\end{aligned}
$$

Incentive Problem: A bank financed at least partially with debt faces a basic incentive problem when it comes to continuing or liquidating its project, similar to the risk-shifting problem of Jensen and Meckling (1976). Suppose that in the initial period $t=0$ a bank has $\eta \in[0,1]$ of equity and raises $1-\eta$ in some form of debt. Denote by $D_{t}$ the face value of this debt at $t=1,2$. After learning about $\theta_{i}$ and $\ell$ in the interim period $t=1$, the bank wants to continue its project whenever the expected equity payoff from continuing is greater than the equity payoff from liquidating:

$$
\begin{aligned}
& \theta_{i}\left(X-(1-\eta) D_{2}\right)>\max \left\{0, \ell-(1-\eta) D_{1}\right\} \\
& \Leftrightarrow \quad \theta_{i}> \begin{cases}\frac{\ell-(1-\eta) D_{1}}{X-(1-\eta) D_{2}} & \text { for } 1-\eta \leq \frac{\ell}{D_{1}} \\
0 & \text { for } 1-\eta>\frac{\ell}{D_{1}}\end{cases}
\end{aligned}
$$

Unless the bank is fully equity financed $(\eta=1)$, its decision doesn't correspond to the efficient one of continuing if and only if $\theta_{i}>\ell / X$. In particular, as long as $D_{1} X>D_{2} \ell$, i.e. $X$ sufficiently larger than $\ell$, the bank wants to take excessive risks in the interim period by continuing projects with negative net present value. Since this incentive problem is present for any $\eta<1$, I consider the cleanest case and assume that banks have no initial equity. This assumption abstracts from the choice of leverage to focus purely on the choice of maturity structure.

Uncertainty: There is an aggregate state $s \in\{H, L\}$ with probabilities $p$ and $1-p$, respectively. Conditional on the aggregate state $s$, the banks' success probabilities $\left\{\theta_{i}\right\}$ are i.i.d. with cumulative distribution function $F_{s}$ with full support on $[0,1]$ and continuous density $f_{s}$. The difference between the high state and the low state is that the distribution $F_{H}$ strictly dominates the distribution $F_{L}$ in terms of first-order stochastic dominance:

$$
F_{H}(\theta)<F_{L}(\theta) \text { for all } \theta \in(0,1)
$$


This means that higher success probabilities are more likely in state $H$ than in state $L$ and therefore that banks' projects are positively correlated. Both the aggregate state $s$ and each individual bank's success probability $\theta_{i}$ are realized at the beginning of $t=1$, before the continuation decision about the project, but after the investment decision in $t=0$. The uncertainty about $s$ is referred to as aggregate risk while the uncertainty about $\theta_{i}$ is referred to as idiosyncratic risk. The draw of a distribution $F_{s}$ is 'aggregate' since it the same for every bank while the draw of a success probability $\theta_{i}$ from $F_{s}$ is 'idiosyncratic' since it is independent for every bank, conditional on $s$.

Information: After realization, the aggregate state $s$ is perfectly observed by everyone and therefore common knowledge. In contrast, each creditor $j i$ observes only a noisy signal $x_{j i}=\theta_{i}+\sigma \varepsilon_{j i}$ about the realization of bank $i$ 's success probability $\theta_{i}$ where $\varepsilon_{j i}$ is i.i.d. across all $j i$ with density $f_{\varepsilon}$ on $\mathbb{R}$ and $\sigma$ is positive but arbitrarily small. The signal density $f_{\varepsilon}$ is assumed log-concave to guarantee the monotone likelihood ratio property (MLRP).

Liquidation Value: The liquidation value for the banks' assets is determined endogenously from a downward-sloping aggregate demand for liquidated assets. If assets are liquidated, they are reallocated to an alternative use with decreasing marginal productivity. For a mass $\phi \in[0,1]$ of assets sold off by all banks in total, this implies a liquidation value $\ell(\phi)$ given by a continuous and strictly decreasing function $\ell:[0,1] \rightarrow[\underline{\ell}, \bar{\ell}] \subset[0,1]$ which corresponds to the assets' marginal product in the alternative use.

We can think of the assets literally being reallocated to a less productive sector, e.g. as in Kiyotaki and Moore (1997) or Lorenzoni (2008). This interpretation is in line with evidence such as Sandleris and Wright (2014) who show that a large part of the decrease in productivity in financial crises can be attributed to misallocated resources. Alternatively, the reallocation can be interpreted as a move within the financial sector as documented by He, Khang, and Krishnamurthy (2010). In this case, the reallocation can have real effects by influencing risk premia (He and Krishnamurthy, 2012, 2013) or hurdle rates for new investment (Stein, 2012). ${ }^{4}$

\footnotetext{
${ }^{4}$ For evidence on the reduced supply of bank lending to the real sector during the financial crisis of 2007-09 see, e.g. Ivashina and Scharfstein (2010), Adrian, Colla, and Shin (2013) or Bord and Santos (2014).
} 
To fix ideas, let the alternative use be a sector with a continuum of firms $k \in[0,1]$ that have identical concave production functions $Y\left(\phi_{k}\right)$. In the alternative sector, firm $k$ takes the price $\ell$ of its inputs as given and solves:

$$
\max _{\phi_{k}}\left\{Y\left(\phi_{k}\right)-\ell \times \phi_{k}\right\}
$$

Competitive equilibrium in the alternative sector therefore implies $\ell=Y^{\prime}(\phi)$.

Due to the exogenous correlation in the banks' $\theta_{i}$ s the model generates fluctuations in equilibrium asset sales $\phi$ across the aggregate states $H$ and $L$. This implies volatility in the endogenous liquidation value with two different values $\ell_{H}=\ell\left(\phi_{H}\right)$ and $\ell_{L}=$ $\ell\left(\phi_{L}\right)$ in the two states. Hence, there is an indirect link between an individual project's expected payoff and the liquidation value of its assets: In the high state, both the average project's expected payoff (exogenous) and the liquidation value (endogenous) are greater than in the low state:

$$
E_{H}[\theta X]>E_{L}[\theta X] \text { and } \ell_{H}>\ell_{L}
$$

Financing: Each bank has to raise the entire investment amount of 1 through loans from risk neutral and competitive creditors in $t=0$. A bank can choose any combination of long-term debt and short-term debt to finance its project. ${ }^{5}$ Bank $i$ 's long-term debt matures in the final period $t=2$ at a face value of $B_{i}$. Short-term debt has to be rolled over in the interim period $t=1$ at a face value of $R_{i}$ and - if rolled overmatures at a face value of $R_{i}^{2}$ in the final period $t=2$. Instead of rolling over in $t=1$, a short-term creditor $j i$ has the right to demand payment of $R_{i} \cdot{ }^{6}$ This creates the possibility of the bank failing in $t=1$ if the withdrawals from short-term creditors leave it with insufficient resources to repay the remaining creditors in $t=2$. If a bank fails in $t=1$, all creditors - short term and long term - share the proceeds of liquidation but short-term creditors who did not withdraw pay a $\operatorname{cost} \delta>0$, e.g. to lawyers in order

\footnotetext{
${ }^{5}$ I rule out other forms of financing but there are several different ways to justify debt financing endogenously, see Innes (1990), DeMarzo and Duffie (1999), Geanakoplos (2010) or Dang, Gorton, and Holmström (2012).

${ }^{6}$ The assumption that the short-term interest rate $R_{i}$ does not adjust in the interim period isolates the rollover decision as the key margin of adjustment. This is consistent with the evidence of Copeland, Martin, and Walker (2014) who document in the tri-party repo market, a key funding market for financial intermediaries, that lenders simply refused to roll over funding to troubled banks rather than adjusting interest rates.
} 


\begin{tabular}{|c|c|c|}
\hline$t=0$ & $t=1$ & $t=2$ \\
\hline $\begin{array}{l}\text { - Banks raise financ- } \\
\text { ing }\left(\alpha_{i}, 1-\alpha_{i}\right) \\
\text { - Banks invest in } \\
\text { projects }\end{array}$ & $\begin{array}{l}\text { - } s \text { and }\left\{\theta_{i}\right\} \text { realized } \\
\text { - Each bank's ST creditors } \\
\text { demand } R_{i} \text { or roll over } \\
\text { - Measure } \phi_{s} \text { of banks } \\
\text { liquidated at } \ell\left(\phi_{s}\right)\end{array}$ & $\begin{array}{l}\text { - Remaining projects suc- } \\
\text { ceed or fail based on }\left\{\theta_{i}\right\} \\
\text { - Successful banks pay } \\
\text { creditors } R_{i}^{2} \text { and } B_{i}\end{array}$ \\
\hline
\end{tabular}

Figure 2: Time-line for the whole economy

to receive sufficient consideration in the bankruptcy process.

Denoting by $\alpha_{i} \in[0,1]$ the fraction of bank $i$ 's project financed by short-term debt, the bank's choice of debt maturity structure in $t=0$ is denoted by the combination of short-term and long-term debt $\left(\alpha_{i}, 1-\alpha_{i}\right)$. The interest rates $R_{i}$ and $B_{i}$ are determined endogenously, taking into account both the fundamental idiosyncratic and aggregate risk, as well as the equilibrium rollover risk arising from the bank's maturity structure.

Definition of Equilibrium: The model combines a competitive equilibrium among banks choosing their maturity structures with a Bayesian Nash equilibrium played among the creditors of all banks. An equilibrium therefore consists of maturity structure choices $\alpha_{i}$ for all banks $i \in[0,1]$, strategies $\mathbf{s}_{j i}$ for all creditors $j \in[0,1]$ at all banks $i \in[0,1]$ that assigns an action for every signal in every aggregate state as well as interest rates $\left(R_{i}, B_{i}\right)$ for all banks $i \in[0,1]$ and liquidation values $\ell_{H}, \ell_{L}$ such that:

1. Conditional on the aggregate state $s$ in $t=1$, the creditors' strategies $\left\{\mathbf{s}_{i j}\right\}$ form a Bayesian Nash equilibrium.

2. Each banks' choice of $\alpha_{i}$ in $t=0$ maximizes its expected profit given the resulting creditor equilibrium at $t=1$.

3. Short-term and long-term creditors break even in expectation.

4. Liquidation values are given by the marginal product of assets in the secondary sector.

Figure 2 illustrates the timeline of the whole economy. Since no decisions are made in the final period $t=2$, the first step in solving the model is to analyze the rollover 
decision of short-term creditors in the interim period $t=1$ for given maturity structures $\left(\alpha_{i}, 1-\alpha_{i}\right)$. The second step is to derive the optimal choice of maturity structure in the initial period $t=0$, taking into account the resulting outcomes in periods $t=1,2$. Finally, the model is closed in general equilibrium by determining the endogenous liquidation values.

\section{Individual Bank}

I first consider the situation of an individual bank, taking as given the behavior of all other banks and the resulting equilibrium liquidation values. To reduce notational clutter I drop the bank index $i$ for now.

\subsection{Endogenous Rollover Risk}

To solve the individual bank's problem, the first step is to analyze the rollover decision of a bank's short-term creditors in the interim period $t=1$, after both the draw of the aggregate state $s$ resulting in the distribution $F_{s}$ and the draw of the bank's idiosyncratic success probability $\theta$ from the distribution $F_{s}$.

Denoting the fraction of short-term creditors who withdraw their loans by $\lambda$, the bank has to liquidate enough of the project to raise $\alpha \lambda R$ for repayment. With a liquidation value of $\ell$, this leaves the bank with a fraction $1-\alpha \lambda R / \ell$ of its assets to satisfy creditors at $t=2$. The bank will therefore be illiquid and fail at $t=1$ whenever the payoff of the remaining assets - if the project is successful - is insufficient:

$$
\begin{aligned}
\left(1-\frac{\alpha \lambda R}{\ell}\right) X<(1-\lambda) \alpha R^{2}+(1-\alpha) B \\
\Leftrightarrow \quad \lambda>\frac{X-\alpha R^{2}-(1-\alpha) B}{\alpha R\left(\frac{X}{\ell}-R\right)} \equiv \hat{\lambda}(\alpha, \ell)
\end{aligned}
$$

First, consider the case where the bank remains liquid. In this case, short-term creditors who roll over will be repaid $R^{2}$ if the project is successful in $t=2$. Given the project's success probability $\theta$, this implies an expected payoff of $\theta R^{2}$ from rolling over. Short-term creditors who withdraw simply receive $R$ in $t=1$. Next, consider the case where the bank becomes illiquid and fails at $t=1$. In this case all creditors share the proceeds of liquidation $\ell$ but short-term creditors who rolled over pay a $\operatorname{cost} \delta>0$. 


\begin{tabular}{c|c|c|c|}
\multicolumn{1}{c}{} & \multicolumn{2}{c}{$\theta \leq \bar{\theta}$} \\
\cline { 2 - 4 } roll over & $\theta>\bar{\theta}$ & $\lambda \leq \hat{\lambda}(\alpha, \ell)$ & $\lambda>\hat{\lambda}(\alpha, \ell)$ \\
\cline { 2 - 4 } withdraw & $R^{2}$ & $\theta R^{2}$ & $\ell-\delta$ \\
\cline { 2 - 4 } & $R$ & $R$ & $\ell$ \\
\cline { 2 - 4 } & & &
\end{tabular}

Figure 3: Payoffs of short-term creditors

Finally, similar to Goldstein and Pauzner (2005), I assume a $\bar{\theta}<1$ (but arbitrarily close to 1$)$ such that for $\theta \in(\bar{\theta}, 1]$ the project matures early and pays off $X$ in $t=1$. Figure 3 summarizes the payoffs of short-term creditors.

These payoffs create the classic coordination problem at the heart of panic-based bank runs first analyzed by Bryant (1980) and Diamond and Dybvig (1983). ${ }^{7}$ With perfect information about the fundamentals $\theta$ and $\ell$ and as long as they are not too bad or too good, i.e. $1 / R<\theta<\bar{\theta}$, there are multiple equilibria: If an individual creditor expects all other creditors to roll over and the bank to remain liquid, it is individually rational to roll over as well since $\theta R^{2}>R$. Everyone rolling over and the bank remaining liquid is therefore an equilibrium. At the same time, if an individual creditor expects all other creditors to withdraw and the bank to fail, it is individually rational to withdraw as well since $\ell>\ell-\delta$. Everyone withdrawing and the bank failing is therefore also an equilibrium.

From a modeling perspective this indeterminacy is somewhat of a mixed blessing, often resulting in the assumption that a run only happens when it is the only equilibrium (Allen and Gale, 1998; Diamond and Rajan, 2000). For the payoffs in Figure 3 this corresponds to the case of very bad fundamentals $(\theta<1 / R)$ where withdrawing is a dominant strategy and the multiplicity disappears with only the run equilibrium remaining. However, many elements of financial regulation and emergency policy measures are rooted in the belief that panic-based runs are a real possibility. Goldstein (2013) discusses the empirical evidence and points out that a clean distinction between fundamentals and panic is impossible since the worse the fundamentals, the more likely panic-based runs are.

\footnotetext{
${ }^{7}$ Classic bank run models rely on the sequential service constraint inherent in deposit contracts. My setup is more representative of market-based funding, without a sequential service constraint, where self-fulfilling rollover crises have been studied at least since Cole and Kehoe (2000).
} 
In this paper, I therefore use the global game approach which eliminates common knowledge among players to resolve the multiplicity of equilibria. This has two key advantages: First, it delivers a unique Bayesian Nash equilibrium outcome for the creditor game played in $t=1$ that is based entirely on the realization of the fundamentals $\theta$ and $\ell$. Second, the implied ex-ante rollover risk is well-defined and varies continuously with the the bank's maturity structure $\alpha$, the key choice variable in $t=0$.

The setting of this paper, where global games played at many banks simultaneously are embedded in a general equilibrium framework, complicates the analysis considerably. The liquidation value $\ell$ enters the payoffs of creditors at all banks and is determined by the creditor interaction at all banks. Therefore all creditors at all banks are, in fact, interacting in a single "universal global game." As a result, for arbitrary strategies played by creditors at other banks, the liquidation value faced by the creditors at a particular bank may not be deterministic. However, I show in the proof of Proposition 1 in the appendix that even for arbitrary uncertainty about $\ell$, taking the limit as the noise parameter $\sigma \rightarrow 0$ yields a unique Bayesian Nash equilibrium at any individual bank that retains the standard properties laid out in Morris and Shin (2003). This implies that in a symmetric competitive equilibrium among banks in $t=0$, the liquidation value conditional on the aggregate state in $t=1$ is deterministic, justifying the simplified exposition of the global game among creditors of an individual bank that follows.

Proposition 1. In a symmetric competitive equilibrium among banks in $t=0$ and for $\sigma \rightarrow 0$, the unique Bayesian Nash equilibrium among short-term creditors in $t=1$ is in switching strategies around a threshold $\hat{\theta}$ given by:

$$
\hat{\theta}=\frac{1}{R}+\left(\frac{1}{\hat{\lambda}(\alpha, \ell)}-1\right) \frac{\delta}{R^{2}}
$$

For realizations of $\theta$ above $\hat{\theta}$, all short-term debt is rolled over and the bank remains liquid. For realizations of $\theta$ below $\hat{\theta}$, all short-term debt is withdrawn and the bank fails.

(All proofs are relegated to the appendix.) The global game equilibrium is symmetric in switching strategies around a signal threshold $\hat{\theta}$ such that each creditor rolls over for all signals above the threshold and withdraws for all signals below. The equilibrium switching point $\hat{\theta}$ is determined by the fact that for a creditor exactly at the switching 
point the expected payoff from rolling over has to equal the expected payoff from withdrawing. Given the payoffs in Figure 3, this indifference condition for a signal $x_{j}=\hat{\theta}$ is:

$$
\begin{aligned}
& \overbrace{\operatorname{Pr}[\text { liquid } \mid \hat{\theta}] \times \hat{\theta} R^{2}+\operatorname{Pr}[\text { illiquid } \mid \hat{\theta}] \times(\ell-\delta)}^{\text {roll over }} \\
& =\underbrace{\operatorname{Pr}[\text { liquid } \mid \hat{\theta}] \times R+\operatorname{Pr}[\text { illiquid } \mid \hat{\theta}] \times \ell}_{\text {withdraw }}
\end{aligned}
$$

The main uncertainty faced by an individual creditor is about the fraction $\lambda$ of other creditors who withdraw since it determines if the bank remains liquid or becomes illiquid. In the limit, as signal noise $\sigma$ goes to 0 , the distribution of $\lambda$ conditional on being at the switching point $\hat{\theta}$ becomes uniform on $[0,1]$. Combined with the fact that the bank remains liquid if and only if $\lambda \leq \hat{\lambda}(\alpha, \ell)$ this means that the indifference condition (2) simplifies to:

$$
\hat{\lambda}(\alpha, \ell) \hat{\theta} R^{2}+(1-\hat{\lambda}(\alpha, \ell))(\ell-\delta)=\hat{\lambda}(\alpha, \ell) R+(1-\hat{\lambda}(\alpha, \ell)) \ell
$$

Solving for $\hat{\theta}$ yields the equilibrium switching point (1).

The simple structure of the equilibrium highlights three important characteristics of a bank's ex-ante rollover risk, i.e. before the uncertainty about $\theta$ and $\ell$ is resolved. This rollover risk is the probability that the bank will suffer a run in the interim period and is given by:

$$
\operatorname{Pr}\left[\theta<\frac{1}{R}+\left(\frac{1}{\hat{\lambda}(\alpha, \ell)}-1\right) \frac{\delta}{R^{2}}\right]
$$

First, the rollover risk depends on the fraction of short-term debt $\alpha$, both directly through $\hat{\lambda}(\alpha, \ell)$ as well as indirectly through the endogenous $R$. The direct effect is positive since $\frac{\partial}{\partial \alpha} \hat{\lambda}(\alpha, \ell)<0$ : Having a balance sheet that relies more heavily on shortterm debt makes the bank more vulnerable to runs since it increases the total amount of withdrawals the bank may face. As will become clear in Lemma 1 below, the overall effect of $\alpha$ remains positive when also taking into account the effect of $\alpha$ on $R$. By choosing its debt maturity structure, the bank can therefore directly influence its rollover risk.

Second, once the maturity structure is in place, whether the bank suffers a run or 
not depends on both sources of risk, idiosyncratic and aggregate. Since both $\theta$ and $\ell$ in expression (3) are random variables and $\frac{\partial}{\partial \ell} \hat{\lambda}(\alpha, \ell)>0$, a run can be triggered by bad news about the project's expected payoff (low $\theta$ ), or by bad news about the liquidation value (low $\ell$ ). When deciding whether to roll over, creditors worry about a low $\theta$ because it means they are less likely to be repaid in $t=2$, should the bank remain liquid. In addition, they worry about a low $\ell$ because it means the bank can withstand less withdrawals and is more likely to become illiquid in $t=1$. The worry about $\theta$ is about future insolvency while the worry about $\ell$ is about current illiquidity.

Third, the two sources of risk interact in determining the bank's rollover risk. In particular, the bank is more vulnerable to idiosyncratic risk for a low realization of the liquidation value. The destabilizing effect of a low liquidation value means that the bank suffers runs for idiosyncratic news that would have left it unharmed had the liquidation value been higher. If the liquidation value fluctuates with the aggregate state, a bank will be more vulnerable to runs in the low aggregate state than in the high aggregate state, for any given ex-ante maturity structure. This effect will play a crucial role in the inefficiency result of this paper.

\subsection{Debt Maturity without Aggregate Risk}

The second step in the backwards induction is to derive the bank's choice of maturity structure in the initial period $t=0$. To establish the efficiency benchmark, I start with the case of no aggregate risk, that is the banks' success probabilities are drawn from a distribution $F$, and the liquidation value $\ell$ is deterministic.

In the initial period $t=0$, short-term and long-term creditors as well as the bank anticipate what will happen in the following periods. This means that the face values of short-term debt and long-term debt, $R$ and $B$, have to guarantee that investors break even. When choosing its debt maturity structure $(\alpha, 1-\alpha)$, the bank takes into account the effect of $\alpha$ on the face values $R$ and $B$, as well as on the rollover risk from the global-game equilibrium in $t=1$.

Given the equilibrium threshold $\hat{\theta}$ as defined by (1), the break-even constraints for 
the bank's creditors take a simple form:

$$
\begin{array}{ll}
\text { Short-term creditors: } & F(\hat{\theta}) \ell+\int_{\hat{\theta}}^{1} \theta R^{2} d F(\theta)=1 \\
\text { Long-term creditors: } & F(\hat{\theta}) \ell+\int_{\hat{\theta}}^{1} \theta B d F(\theta)=1
\end{array}
$$

For realizations of $\theta$ below $\hat{\theta}$, all short-term creditors refuse to roll over and there is a run on the bank in $t=1$. In this case, which happens with probability $F(\hat{\theta})$, the bank has to liquidate all its assets and each creditor receives an equal share of the liquidation proceeds $\ell$. For realizations of $\theta$ above $\hat{\theta}$, all short-term creditors roll over and the bank continues to operate the project. In this case, the creditors receive the face value of their loan, the compounded short-term $R^{2}$ and the long-term $B$, but only if the project is successful in $t=2$ which happens with probability $\theta$.

Note that the break-even constraints (4) and (5) immediately imply that the returns on long-term and short-term debt are equal, that is, $R^{2}=B$. This is due to the fact that, in equilibrium, all creditors receive the same payoffs. An important implication is that, in this model, the use of short-term debt is purely for disciplining purposes. This is in contrast to other models where short-term debt is inherently cheaper and loading up on it lowers a bank's financing cost.

The ex-ante expected payoff of the bank can be derived in a similar way. For realizations $\theta \leq \hat{\theta}$ there is a run by short-term creditors in the interim period and the bank's payoff is zero. For realizations $\theta>\hat{\theta}$ there is no run in $t=1$ and with probability $\theta$ the project is successful in $t=2$. In this case the bank receives the project's cash flow $X$ and has to repay its liabilities $\alpha R^{2}+(1-\alpha) B$. The bank's expected payoff therefore is:

$$
\int_{\hat{\theta}}^{1} \theta\left(X-\alpha R^{2}-(1-\alpha) B\right) d F(\theta)
$$

Substituting in the values for $R$ and $B$ required by the break-even constraints (4) and (5), the bank's payoff becomes: ${ }^{8}$

$$
F(\hat{\theta}) \ell+\int_{\hat{\theta}}^{1} \theta X d F(\theta)-1
$$

\footnotetext{
${ }^{8}$ Note that $X$ is guaranteed to be sufficient to cover the face value of liabilities $\alpha R^{2}+(1-\alpha) B$. Solving (4) and (5) for $R^{2}$ and $B$, and substituting in, we have that $X-\alpha R^{2}-(1-\alpha) B>0$ is implied by $F(\hat{\theta}) \ell+\int_{\hat{\theta}}^{1} \theta X d F(\theta)-1>0$, i.e. if the bank is viable.
} 
The first term in (6) is the economic value realized in the states where the project is liquidated; the second term is the expected economic value realized in the states where the project is continued; the third term is the initial cost of investment. Due to the rational expectations and the competitive creditors, the bank receives the entire economic surplus of its investment opportunity, given the rollover-risk threshold $\hat{\theta}$. Since it receives the entire economic surplus, the bank fully internalizes the effect of its maturity structure choice on the efficiency of the rollover outcome.

Before analyzing the bank's choice of maturity structure, one complication remains: The critical value $\hat{\theta}$ derived from the rollover equilibrium in $t=1$ depends on the short-term interest rate $R$. This interest rate, in turn, is set in $t=0$ by the break-even condition which anticipates the rollover threshold $\hat{\theta}$. Therefore equations (1) and (4) jointly determine $\hat{\theta}$ and $R$ for a given $\alpha$. Our variable of interest is the rollover threshold $\hat{\theta}$ and how it depends on the ex-ante choice of $\alpha$, taking into account the endogeneity of $R$.

Lemma 1. Equations (1) and (4) implicitly define the interim rollover threshold $\hat{\theta}$ as a function of the ex-ante maturity structure $\alpha$. The mapping $\hat{\theta}(\alpha)$ is one-to-one and satisfies $d \hat{\theta} / d \alpha>0$.

This lemma establishes the direct link between $\hat{\theta}$ and $\alpha$. In choosing its maturity structure $\alpha$, the bank effectively chooses a rollover-risk threshold $\hat{\theta}(\alpha)$; the more shortterm debt the bank takes on in $t=0$, the higher is the rollover risk it faces in $t=1$. The following proposition characterizes the optimal choice of the bank maximizing its expected payoff (6) subject to the link between maturity structure and rollover risk.

Proposition 2. Without aggregate risk, the bank chooses an optimal maturity structure $\alpha^{*}$ that implements the efficient liquidation policy:

$$
\hat{\theta}\left(\alpha^{*}\right)=\frac{\ell}{X}
$$

The bank uses short-term debt as a disciplining device to implement a liquidation threshold $\hat{\theta}$ maximizing its payoff. Since the payoff corresponds to the project's full economic surplus, the bank's objective is the same as a social planner's. In the case without aggregate risk, subjecting itself to the market discipline of rollover risk allows the bank to overcome its incentive problem and achieve the first-best policy. Depending 


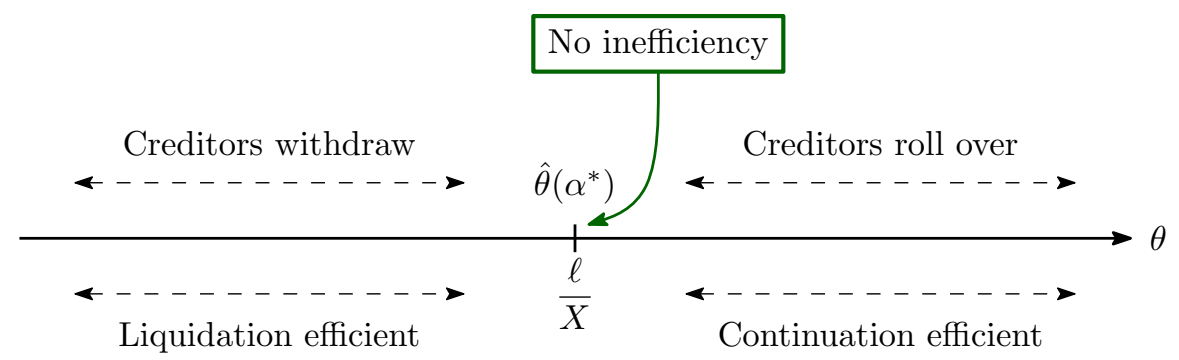

Figure 4: Implemented and efficient rollover risk without aggregate risk

on the project's expected payoff after observing $\theta$, the first-best policy requires either to continue with the project or to abandon it and put the liquidated assets to alternative use. Continuation is efficient whenever the project's expected payoff is greater than the liquidation value, $\theta X>\ell$, and liquidation is efficient whenever $\theta X<\ell$. Figure 4 illustrates how the bank uses market discipline to implement the first-best policy. Creditors roll over - allowing the project to continue - for $\theta>\ell / X$ and withdrawforcing the project to be liquidated-for $\theta<\ell / X$, exactly as required for efficiency. However, this efficiency breaks down in the case with aggregate risk discussed next.

This result has important implications for the comparative statics of the bank's rollover risk. While the rollover-risk threshold $\hat{\theta}$ for a given maturity structure $\alpha$ is decreasing in the liquidation value $\ell$, the efficient liquidation threshold $\ell / X$ is increasing in the liquidation value $\ell$. As discussed in Section 3.1 above, for a given maturity structure, a higher liquidation value has a stabilizing effect on the bank and therefore reduces rollover risk. In terms of efficiency, however, a higher liquidation value means that there are better alternative uses for the project's assets which raises the bar in terms of expected project payoff to justify continuing. Since the bank is able to implement the optimal liquidation policy, ceteris paribus a higher liquidation value will cause it to increase rollover risk by choosing a maturity structure more reliant on short-term debt. This is reflected in the fact that $\alpha^{*}$ is increasing in $\ell$.

\subsection{Debt Maturity with Aggregate Risk}

I now analyze the situation of an individual bank facing aggregate risk. With probability $p$ the state is high, $s=H$, which means that the success probability is drawn from the distribution $F_{H}$ and the liquidation value is $\ell_{H}$. With probability $1-p$ the state is low, $s=L$, with distribution $F_{L}$ and liquidation value $\ell_{L}$. State $H$ is the "good" state since 
$F_{H}$ first-order stochastically dominates $F_{L}$ and since $\ell_{H}>\ell_{L} \cdot{ }^{9}$

The variation in liquidation values due to aggregate risk has two main implications for the bank. The first is that the first-best policy - whether to continue or liquidate the project - is affected by the realization of $\ell$. For the low liquidation value $\ell_{L}$ the project should only be continued if $\theta X>\ell_{L}$, while for the high liquidation value $\ell_{H}$ the condition is $\theta X>\ell_{H}$. There are now two cutoffs for the project's expected payoff: the bar for $\theta X$ to justify continuing is higher in state $H$ than in state $L$ because $\ell_{H}>\ell_{L}$ indicates that alternative uses for the bank's assets are more valuable in state $H$ than in state $L$. This means that for realizations of the project's success probability $\theta$ in the interval $\left[\ell_{L} / X, \ell_{H} / X\right]$, efficiency calls for liquidation if the economy is in the good state and for continuation if the economy is in the bad state.

The second implication of aggregate risk is that the creditor coordination game is different depending on the aggregate state. There are now two equilibrium switching points, $\hat{\theta}_{H}$ and $\hat{\theta}_{L}$, one for each realization of $s$ :

$$
\hat{\theta}_{H}=\frac{1}{R}+\left(\frac{1}{\hat{\lambda}\left(\alpha, \ell_{H}\right)}-1\right) \frac{\delta}{R^{2}} \quad \text { and } \quad \hat{\theta}_{L}=\frac{1}{R}+\left(\frac{1}{\hat{\lambda}\left(\alpha, \ell_{L}\right)}-1\right) \frac{\delta}{R^{2}}
$$

If the liquidation value is high, each creditor is less concerned about the other creditors withdrawing their loans and therefore more willing to roll over than when the liquidation value is low. Therefore, the bank will be more stable and less likely to suffer a run by its short-term creditors if the liquidation value is high, which is reflected in the rollover-risk threshold being lower:

$$
\hat{\theta}_{H}<\hat{\theta}_{L}
$$

As in the case without aggregate risk, the bank receives the entire economic surplus of its project, given the liquidation resulting from its maturity structure:

$$
p\left(F_{H}\left(\hat{\theta}_{H}\right) \ell_{H}+\int_{\hat{\theta}_{H}}^{1} \theta X d F_{H}(\theta)\right)+(1-p)\left(F_{L}\left(\hat{\theta}_{L}\right) \ell_{L}+\int_{\hat{\theta}_{L}}^{1} \theta X d F_{L}(\theta)\right)-1
$$

The bank again chooses a maturity structure $\alpha$ to maximize its expected payoff, now

\footnotetext{
${ }^{9}$ Note that the liquidation values are endogenous in equilibrium, as derived in Section 4 below. Here, the analysis is from the perspective of an individual bank which takes the equilibrium values $\ell_{H}, \ell_{L}$ as given.
} 

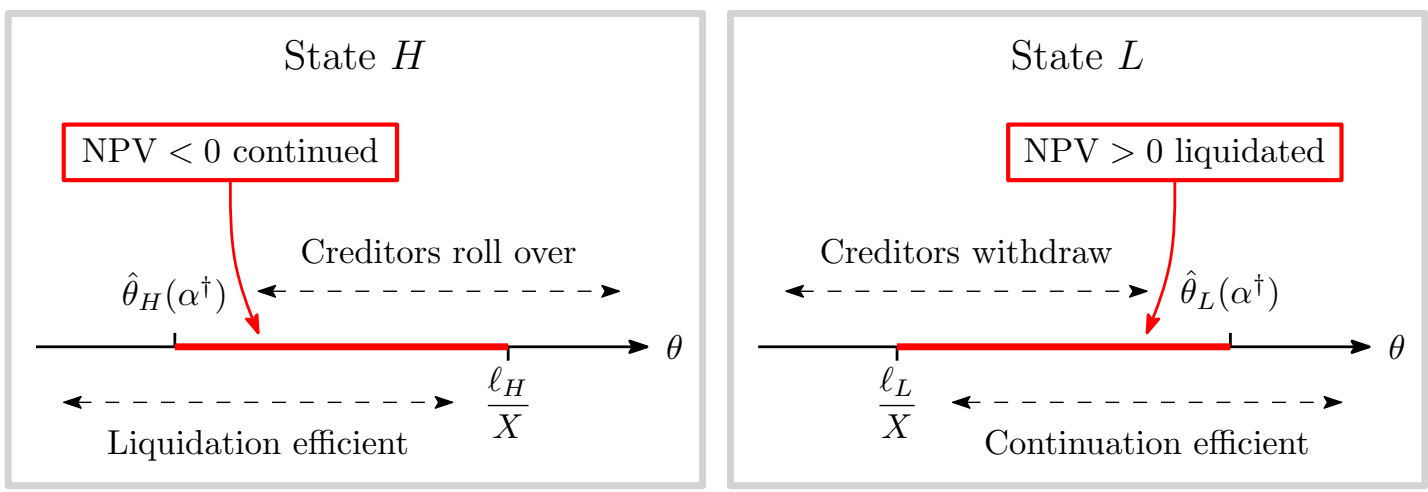

Figure 5: Two-sided inefficiency with aggregate risk

taking into account the effect it has on the two rollover thresholds $\hat{\theta}_{H}(\alpha)$ and $\hat{\theta}_{L}(\alpha) .{ }^{10}$

Proposition 3. For given liquidation values $\ell_{H}>\ell_{L}$, the bank chooses an optimal maturity structure $\alpha^{\dagger}$ resulting in a two-sided inefficiency:

$$
\hat{\theta}_{H}\left(\alpha^{\dagger}\right)<\frac{\ell_{H}}{X} \quad \text { and } \quad \hat{\theta}_{L}\left(\alpha^{\dagger}\right)>\frac{\ell_{L}}{X}
$$

For $s=H$, negative-NPV projects are continued whenever $\theta \in\left(\hat{\theta}_{H}\left(\alpha^{\dagger}\right), \ell_{H} / X\right)$ while for $s=L$, positive-NPV projects are liquidated whenever $\theta \in\left(\ell_{L} / X, \hat{\theta}_{L}\left(\alpha^{\dagger}\right)\right)$.

The key effect of aggregate risk is that it drives a wedge between the efficient liquidation policy and any achievable liquidation policy. The effectiveness of using the maturity structure to eliminate the incentive problem and to implement an efficient liquidation policy is undermined when aggregate risk is added to the bank's idiosyncratic risk. It is important to note that there are efficiency losses for both realizations of the liquidation value, as illustrated in Figure 5. In state $H$, excessively risky projects that should be liquidated because they have negative net present value are continued. In state $L$ on the other hand, valuable projects that should be continued because they have positive net present value are liquidated at fire-sale prices.

The two-sided inefficiency comes from the ambivalent role played by the liquidation value of the bank's assets. A high liquidation value makes the bank less vulnerable to runs but at the same time, the high liquidation value raises the bar in terms of alternate

\footnotetext{
${ }^{10}$ Depending on parameter values, it may be globally optimal to choose a maturity structure that prevents any liquidation in one or both aggregate states. I focus on the more interesting case where the optimal maturity structure implies liquidation in both aggregate states.
} 
uses for the bank's assets which worsens the incentive problem. Exactly the opposite happens in bad aggregate states where the liquidation value is low. This means that the market-discipline effect of short-term debt is weak in the states where it is needed more and is strong in the states where it is needed less.

\section{General Equilibrium and Amplification}

After focusing on the situation of an individual bank that takes liquidation values as given, I now derive the general equilibrium with a unit measure of banks where liquidation values are determined endogenously. Specifically, the liquidation value depends on the mass of assets $\phi \in[0,1]$ sold off by all banks in total and is given by $\ell(\phi)$ with $\ell^{\prime}(\phi)<0$.

\subsection{General Equilibrium without Aggregate Risk}

It is instructive to start with the case of no aggregate risk. The two equations that jointly define the critical value $\hat{\theta}$ as a function of the maturity structure $\alpha$ - the indifference condition (1) and the break-even constraint (4)-both depend on the liquidation value $\ell$ which is a function of aggregate asset sales $\phi$. Writing this relationship as $\hat{\theta}(\alpha, \phi)$ makes clear the dependence of the implemented rollover risk on both the individual bank's $\alpha$ as well as the aggregate $\phi$. A competitive bank's optimization as characterized in Proposition 2 takes the value of $\phi$ as given, resulting in the maturity structure $\alpha^{*}(\phi)$ and the implemented threshold $\hat{\theta}\left(\alpha^{*}(\phi), \phi\right)$.

All banks are identical ex ante, so the competitive equilibrium is symmetric with $\alpha_{i}^{*}=\alpha_{i^{\prime}}^{*}$ for all banks $i, i^{\prime}$. Given that there is a unit measure of banks and that the success probabilities $\left\{\theta_{i}\right\}$ are i.i.d., the aggregate mass $\phi$ of assets sold is equal to the fraction of banks with realizations $\theta_{i} \leq \hat{\theta}\left(\alpha^{*}(\phi), \phi\right)$ who experience a run by their short-term creditors and have to liquidate their assets. The competitive equilibrium value $\phi^{\mathrm{CE}}$ is therefore given by a fixed point:

$$
\phi^{\mathrm{CE}}=F\left(\hat{\theta}\left(\alpha^{*}\left(\phi^{\mathrm{CE}}\right), \phi^{\mathrm{CE}}\right)\right)
$$

We want to compare the competitive equilibrium allocation to the first-best allocation to assess the efficiency properties. The first-best allocation simply equates the 
marginal product of assets in alternative use with the expected payoff of the marginal asset in the banking sector, $Y^{\prime}\left(\phi^{\mathrm{FB}}\right)=\hat{\theta}^{\mathrm{FB}} X$. Using the liquidation value notation, the first-best allocation is therefore characterized by the fixed point:

$$
\phi^{\mathrm{FB}}=F\left(\frac{\ell\left(\phi^{\mathrm{FB}}\right)}{X}\right)
$$

Proposition 4. Without aggregate risk, the competitive equilibrium allocation achieves the first-best allocation.

This efficiency result may seem surprising. First, it is important to point out that liquidation in this model is not inherently inefficient since there are no exogenously assumed liquidation costs or discounts relative to fundamental value, e.g. due to uniformly inferior second-best users (Shleifer and Vishny, 1992). Second, while there is a pecuniary externality - each individual bank not taking into account the effect its liquidation has on the liquidation value facing other banks - it doesn't have a welfare effect. This is similar to a standard general equilibrium model, covered by the first welfare theorem, where competitive producers can perfectly optimize: even though they take the price as given and do not internalize the effect their production decision has, the outcome is efficient. For the pecuniary externality of asset liquidation to have a welfare effect, banks have to be subject to a binding constraint (Dávila, 2015).

\subsection{General Equilibrium with Aggregate Risk}

The case with aggregate risk is only slightly more complicated. There is now a value of $\phi$ for each aggregate state, $\phi_{H}$ and $\phi_{L}$. The critical values $\hat{\theta}_{H}$ and $\hat{\theta}_{L}$ depend on $\phi_{H}$ and $\phi_{L}$, as well as the choice of $\alpha$ characterized in Proposition 3: $\hat{\theta}_{H}\left(\alpha^{\dagger}\left(\phi_{H}, \phi_{L}\right), \phi_{H}\right)$ and $\hat{\theta}_{L}\left(\alpha^{\dagger}\left(\phi_{H}, \phi_{L}\right), \phi_{L}\right)$. The competitive equilibrium is again given by a fixed point, now in two dimensions:

$$
\phi_{H}^{\mathrm{CE}}=F_{H}\left(\hat{\theta}_{H}\left(\alpha^{\dagger}\left(\phi_{H}^{\mathrm{CE}}, \phi_{L}^{\mathrm{CE}}\right), \phi_{H}^{\mathrm{CE}}\right)\right) \quad \text { and } \quad \phi_{L}^{\mathrm{CE}}=F_{L}\left(\hat{\theta}_{L}\left(\alpha^{\dagger}\left(\phi_{H}^{\mathrm{CE}}, \phi_{L}^{\mathrm{CE}}\right), \phi_{L}^{\mathrm{CE}}\right)\right)
$$


The first-best allocation is now conditional on the aggregate state and is characterized by the fixed point:

$$
\phi_{H}^{\mathrm{FB}}=F_{H}\left(\frac{\ell\left(\phi_{H}^{\mathrm{FB}}\right)}{X}\right) \quad \text { and } \quad \phi_{L}^{\mathrm{FB}}=F_{L}\left(\frac{\ell\left(\phi_{L}^{\mathrm{FB}}\right)}{X}\right)
$$

Lemma 2. The first-best allocation with aggregate risk satisfies $\phi_{H}^{\mathrm{FB}}<\phi_{L}^{\mathrm{FB}}$ and therefore $\ell\left(\phi_{H}^{\mathrm{FB}}\right)>\ell\left(\phi_{L}^{\mathrm{FB}}\right)$.

This means that even in the first-best allocation, there is volatility of liquidation values across aggregate states. However, we know from Proposition 3 that individual banks facing liquidation values $\ell_{H}>\ell_{L}$ choose a maturity structure leading to inefficiency in both aggregate states. In general equilibrium, this behavior amplifies volatility of liquidation values.

Proposition 5. With aggregate risk, the competitive equilibrium allocation deviates from the first-best allocation. The equilibrium liquidation value is excessively inflated in the good state, $\ell\left(\phi_{H}^{\mathrm{CE}}\right)>\ell\left(\phi_{H}^{\mathrm{FB}}\right)$, and excessively depressed in the bad state, $\ell\left(\phi_{L}^{\mathrm{CE}}\right)<$ $\ell\left(\phi_{L}^{\mathrm{FB}}\right)$.

The two-sided inefficiency originates in the fact that the liquidation values vary across aggregate states which is true even in the first-best allocation. Then the inefficiency drives a wedge between the optimal and the implementable policy which is self-reinforcing as illustrated in Figure 6. In state $H$ the initial good news that the aggregate distribution of projects is $F_{H}$ increases average bank stability. This makes short-term creditors relatively placid and weakens market discipline. Fewer banks are forced to liquidate and liquidation values are inflated. The high liquidation values, in turn, feed back into increased bank stability, further weakening market discipline and so on. The result of this feedback in the good state is the prevalence of excessive risk-taking with negative NPV projects.

The opposite happens in state $L$ : Bad news about the projects reduces average bank stability; short-term creditors become nervous, strengthening market discipline; more banks are forced to fire-sell their assets which depresses liquidation values; finally, fire-sale conditions in asset markets feed back into reduced bank stability which further tightens market discipline and so on. The result of this feedback loop in the bad state is excessive liquidation of good, positive NPV projects. 

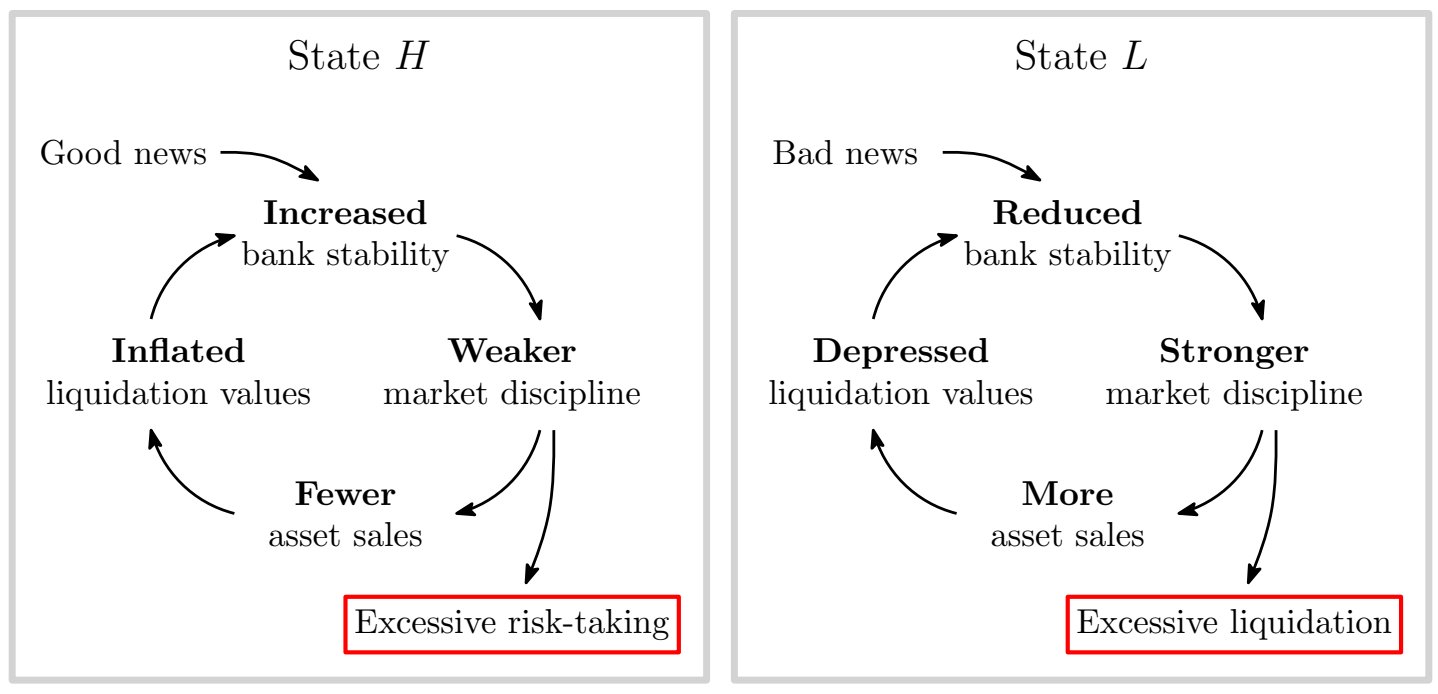

Figure 6: Amplification in both aggregate states

A further question is whether the competitive equilibrium is constrained efficient in an ex ante sense, i.e. whether a social planner who is constrained to choosing a debtmaturity structure for every bank would implement a different allocation. The key detail is that the threshold $\hat{\theta}_{s}$ depends on both $\alpha$ and $\ell_{s}$. An individual bank doesn't have an effect on $\ell_{s}$ and therefore ignores the dependence in its first-order condition. In contrast, a constrained social planner would be choosing $\alpha$ for all banks and would take into account the effect through $\ell_{s}$.

Proposition 6. The level of short-term debt $\alpha^{\mathrm{SP}}$ chosen by a constrained social planner can can be higher or lower than the level of short-term debt $\alpha^{\mathrm{CE}}$ in the competitive equilibrium:

$$
\alpha^{\mathrm{SP}} \lessgtr \alpha^{\mathrm{CE}} \Leftrightarrow \frac{f_{H}\left(\hat{\theta}_{H}^{\mathrm{CE}}\right)}{f_{L}\left(\hat{\theta}_{L}^{\mathrm{CE}}\right)} \lessgtr \frac{\ell^{\prime}\left(\phi_{L}^{\mathrm{CE}}\right)}{\ell^{\prime}\left(\phi_{H}^{\mathrm{CE}}\right)}
$$

A constrained social planner also has to trade off excessive risk in state $H$ against excessive liquidation in state $L$. Proposition 6 shows that whether taking into account the effect of $\alpha$ on the liquidation values $\ell_{H}$ and $\ell_{L}$ leads to more or less short-term debt depends on two effects: (i) the marginal mass of projects at the thresholds $\hat{\theta}_{H}^{\mathrm{CE}}$ and $\hat{\theta}_{L}^{\mathrm{CE}}$ and (ii) the sensitivity of the liquidation values $\ell_{H}$ and $\ell_{L}$ to additional liquidation. For example, reducing the level of short-term debt from the competitive level $\alpha^{\mathrm{CE}}$ leads to less liquidation of positive NPV projects in state $L$ - which increases welfare-but also to more continuation of negative NPV projects in state $H$ - which decreases welfare. 
Which of the two welfare effects dominates then depends on how many projects are affected on the margin, $f_{H}\left(\hat{\theta}_{H}^{\mathrm{CE}}\right)$ compared to $f_{L}\left(\hat{\theta}_{L}^{\mathrm{CE}}\right)$, and on how much the change in $\alpha$ affects the liquidation values and therefore moves the thresholds, $\ell^{\prime}\left(\phi_{H}^{\mathrm{CE}}\right)$ compared to $\ell^{\prime}\left(\phi_{L}^{\mathrm{CE}}\right)$. For the constrained efficient allocation to involve less short-term debt, the density at the threshold in state $L$ has to be large compared to in state $H$ and/or the threshold in state $L$ has to move a lot compared to in state $H$.

\section{Financial Crisis Bonds}

Given the wedge between what is ex post efficient and what is achievable when choosing a debt-maturity structure ex ante, the model points to a lack of state contingency in the exposure to rollover risk ex post. This raises the question why banks don't introduce more state contingency in their short-term debt. An important element of financial intermediation not explicitly modeled in this paper is the provision of liquidity insurance to depositors and other short-term creditors. Introducing state contingency would directly reduce the liquidity insurance and therefore come at a cost, especially to an individual bank acting in isolation.

Instead, state contingency could be introduced into banks' long-term debt. Suppose some of the bank's long-term debt was in the form of "financial crisis bonds." These bonds would be a form of event-linked bonds whose interest and principal payments are conditional on a certain even not occurring - in our case, a financial crisis. If a crisis does occur, the issuer doesn't have to pay back the crisis bond holders. Specifically, denote the fraction of funding raised in $t=0$ through financial crisis bonds be $\gamma \in[0,1]$. Denote by $C$ the bonds' face value in $t=2$ if they are not triggered and 0 otherwise.

Crisis bonds have an effect since the threshold $\hat{\lambda}$ for withdrawals by short-term creditors now depends on whether the crisis bonds are triggered or not. If the bonds are not triggered, the crisis bonds are analogous to regular long-term bonds and the bank fails if

$$
\begin{aligned}
& \left(1-\frac{\alpha \lambda R}{\ell}\right) X<(1-\lambda) \alpha R^{2}+\gamma C+(1-\alpha-\gamma) B \\
& \Leftrightarrow \quad \lambda>\frac{X-\alpha R^{2}-\gamma C-(1-\alpha-\gamma) B}{\alpha R\left(\frac{X}{\ell}-R\right)} \equiv \hat{\lambda}_{0}(\alpha, \gamma, \ell)
\end{aligned}
$$


If the bonds are triggered, however, the bank's debt burden is reduced and it fails if

$$
\begin{aligned}
\left(1-\frac{\alpha \lambda R}{\ell}\right) X<(1-\lambda) \alpha R^{2}+(1-\alpha-\gamma) B \\
\Leftrightarrow \quad \lambda>\frac{X-\alpha R^{2}-(1-\alpha-\gamma) B}{\alpha R\left(\frac{X}{\ell}-R\right)} \equiv \hat{\lambda}_{1}(\alpha, \gamma, \ell)
\end{aligned}
$$

The global game equilibrium among short-term creditors is not impacted beyond the change in $\hat{\lambda}$ by the introduction of financial crisis bonds.

Proposition 7. With financial crisis bonds, the rollover threshold of Proposition 1 depends on whether the bonds are triggered or not,

$$
\hat{\theta}_{H}=\frac{1}{R}+\left(\frac{1}{\hat{\lambda}_{0}\left(\alpha, \gamma, \ell_{H}\right)}-1\right) \frac{\delta}{R^{2}} \quad \text { and } \quad \hat{\theta}_{L}=\frac{1}{R}+\left(\frac{1}{\hat{\lambda}_{1}\left(\alpha, \gamma, \ell_{L}\right)}-1\right) \frac{\delta}{R^{2}}
$$

The reason why crisis bonds are a useful instrument in this model is the additional choice variable $\gamma$ they introduce and the effect it has on the two rollover thresholds. To derive this effect, we have to take into account the joint determination of the rollover thresholds $\hat{\theta}_{H}$ and $\hat{\theta}_{L}$, and the crisis bonds' face value $C$.

Since the bank's crisis bond holders only have a claim in state $H$, their break-even constraint is given by

$$
p\left(F_{H}\left(\hat{\theta}_{H}\right) \ell_{H}+\int_{\hat{\theta}_{H}}^{1} \theta C d F_{H}(\theta)\right)=1
$$

For a given issuance of crisis bonds $\gamma$, the critical value $\hat{\theta}_{H}$ and the bonds' face value $C$ are jointly determined by equations (9) and (10). Analogous to Lemma 1, we have to account for this endogeneity to derive the effect of $\gamma$ on the bank's rollover risk.

Lemma 3. Equations (9) and (10) implicitly define the thresholds $\hat{\theta}_{H}$ and $\hat{\theta}_{L}$ as functions of $\gamma$ (in addition to $\alpha$ ). The mapping is one-to-one and satisfies

$$
\frac{d \hat{\theta}_{H}}{d \gamma}>0 \quad \text { and } \quad \frac{d \hat{\theta}_{L}}{d \gamma}<0
$$

In contrast to more short-term debt $\alpha$, which increases both thresholds $\hat{\theta}_{H}$ and $\hat{\theta}_{L}$, more crisis bonds $\gamma$ increases the threshold $\hat{\theta}_{H}$ but decreases the threshold $\hat{\theta}_{L}$. Crisis 

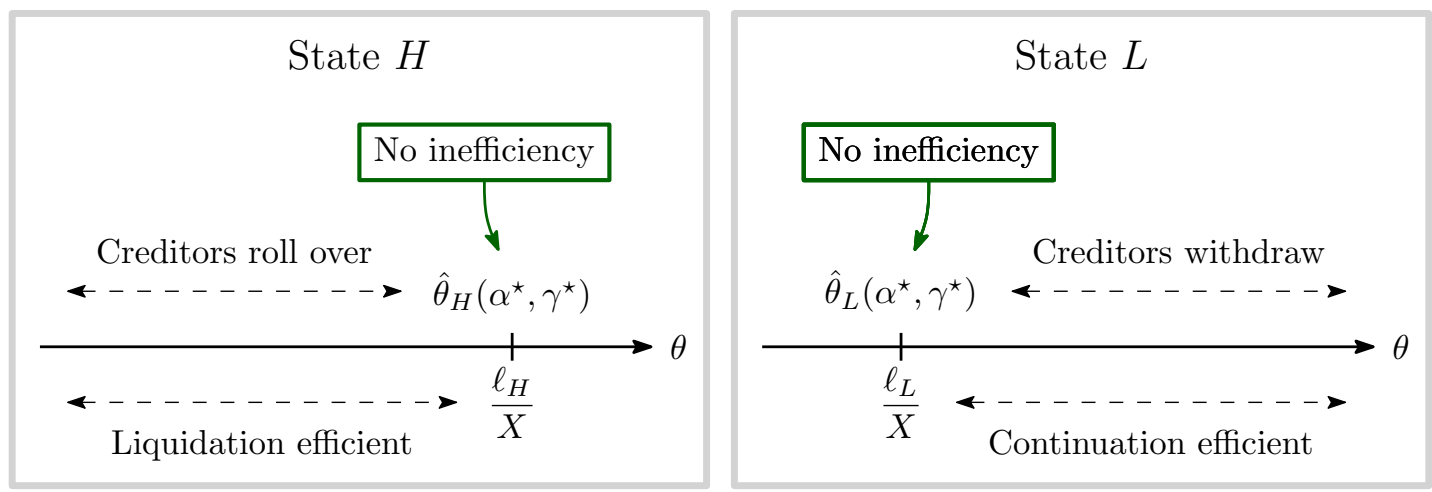

Figure 7: Implemented and efficient rollover risk with crisis bonds

bonds effectively increase the bank's debt burden in the good state $H$, increasing its exposure to rollover risk there, while they decrease the debt burden in the bad state $L$, reducing its exposure to rollover risk there. Crucially, therefore, the bank is able to implement $\hat{\theta}_{H}>\hat{\theta}_{L}$ which is necessary to match the efficient thresholds $\ell_{H} / X>\ell_{L} / X$ but is impossible to achieve with short-term debt alone.

Proposition 8. With crisis bonds, banks choose an optimal liability structure $\left(\alpha^{\star}, \gamma^{\star}\right)$ that implements the efficient liquidation policy under aggregate risk,

$$
\hat{\theta}_{H}\left(\alpha^{\star}, \gamma^{\star}\right)=\frac{\ell_{H}}{X} \quad \text { and } \quad \hat{\theta}_{L}\left(\alpha^{\star}, \gamma^{\star}\right)=\frac{\ell_{L}}{X} .
$$

The competitive equilibrium achieves the first-best allocation.

The introduction of crisis bonds, which affect a bank's debt burden contingent on the aggregate state $s$, reinstates the bank's full control over the liquidation policy conditional on its idiosyncratic state $\theta$ as well as the aggregate state $s$. As illustrated in Figure 7, the bank is able to target the efficient liquidation threshold $\ell_{s} / X$-now for both aggregate states individually. Because banks are unconstrained again, the pecuniary externality has no welfare effects and the competitive equilibrium achieves the first best.

\section{Conclusion}

This paper provides a theoretical foundation for the stylized fact that the market discipline exerted by banks' short-term debt seems too weak during good times and 
too strong during bad times. In the model, the interaction between market discipline and asset values generates amplifying feedback loops that lead to excessive risk taking in good states and fire sales in bad states.

This two-sided inefficiency highlights the lack of state contingency in banks' exposure to rollover risk ex post. Besides an explicit state contingency via a contractual arrangement such as financial crisis bonds or via a "lockbox" of liquidity reserves that is tied to a systemic trigger (Kashyap, Rajan, and Stein, 2008), this model also lends support to implicit state contingency via central banks' interventions in short-term funding markets. By partially substituting for dried-up lending, this policy effectively supports liquidation values in a crisis, thereby preventing some of the inefficient liquidation. Again, it is important that this is a market-wide intervention, that affects all banks equally since it shores up the liquidation values banks face. Interestingly, the state-contingency of such a policy - if anticipated ex ante-may also reduce the risk-taking inefficiency in good states since it relaxes the trade-off banks face between the two inefficiencies.

Finally, the inefficiency mechanism in this paper provides a clear argument for discouraging correlation in banks' assets. This would reduce the volatility in liquidation values and move the allocation towards the first-best with only idiosyncratic risk. For example, a regulatory charge based on a measure like CoVaR (Adrian and Brunnermeier, 2016) would have such an effect. 


\section{Appendix}

Proof of Proposition 1. As explained in the main text, the global game analysis in this paper is complicated by the fact that global games are played at many banks simultaneously and are embedded in a general equilibrium framework. The strategy of this proof is as follows. First, I analyze the game played by an individual bank $i$ 's creditors taking as given arbitrary strategy profiles for the creditors at all other banks $i^{\prime} \neq i$. This is tractable since the only effect the strategies at other banks have on bank $i$ is through the liquidation value $\ell$; for arbitrary strategies at the other banks, the liquidation value faced by bank $i$ may not be deterministic. Based on this insight, I show that even for arbitrary uncertainty in the liquidation value, taking the limit $\sigma \rightarrow 0$ yields a unique strategy for an individual bank's creditors that survives iterative elimination of strictly dominated strategies. This strategy takes the form of a switching strategy around a deterministic switching point. Therefore the creditors at all banks will be using switching strategies, possibly with bank-specific switching points. Next, I show that if all banks have the same maturity structure ex ante, the switching points will be the same across banks. Finally, I show that for symmetric switching points, there will be no uncertainty in the liquidation value (conditional on the aggregate state) and the equilibrium switching point simplifies to the one given defined by (1).

Denote the action "roll over" by 0 and the action "withdraw" by 1 . Then a strategy for creditor $j i$ is a function $\mathbf{s}_{j i}: \mathbb{R} \rightarrow\{0,1\}$ that assigns an action for every signal. Consider an arbitrary profile of strategies $\left\{\mathbf{s}_{j i^{\prime}}\right\}$ of all creditors $j i^{\prime}$ at all other banks $i^{\prime} \neq i$. Arbitrary strategies at other banks may result in arbitrary uncertainty in the liquidation value $\ell$ faced by the creditors of bank $i$. Denote this uncertainty about $\ell$ by the c.d.f. $G$ which is not assumed to be continuous. Importantly, since bank $i$ is atomistic, creditor $j i$ 's signal does not contain any information about $\ell$. Conditional on observing a signal $x_{j i}$, the fundamental $\theta_{i}$ is distributed on $[0,1]$ with distribution:

$$
\mathcal{F}\left(\theta_{i} \mid x_{j i}\right)=\frac{\int_{0}^{\theta_{i}} f(\vartheta) \frac{1}{\sigma} f_{\varepsilon}\left(\frac{x_{j i}-\vartheta}{\sigma}\right) d \vartheta}{\int_{0}^{1} f(\vartheta) \frac{1}{\sigma} f_{\varepsilon}\left(\frac{x_{j i}-\vartheta}{\sigma}\right) d \vartheta}
$$

Note that $\mathcal{F}$ is continuous in $\theta$ and $x$ and that $\frac{\partial}{\partial \theta} \mathcal{F}(\theta \mid x)>0$ and $\frac{\partial}{\partial x} \mathcal{F}(\theta \mid x)<0$ due to MLRP. 
The following arguments generalize the approach of Morris and Shin (2003). To reduce notational clutter, I will drop the subscripts $i$ and $j i$ wherever possible. With uncertainty about $\theta$ and $\ell$, the creditor payoffs in Figure 3 yield an expected payoff difference between withdrawing and rolling over for given $x$ and $\lambda$ of

$$
\begin{aligned}
D(x, \lambda)= & \int_{0}^{\bar{\theta}}\left(\int_{\underline{\ell}}^{\hat{\ell}(\lambda)} \delta d G(\ell)+\int_{\hat{\ell}(\lambda)}^{\bar{\ell}}\left(R-\theta R^{2}\right) d G(\ell)\right) d \mathcal{F}(\theta \mid x) \\
& +\int_{\bar{\theta}}^{1}\left(R-R^{2}\right) d \mathcal{F}(\theta \mid x)
\end{aligned}
$$

where $\hat{\ell}(\lambda)$ is the failure threshold for $\ell$ given by

$$
\hat{\ell}(\lambda) \equiv \frac{\alpha \lambda R X}{X-(1-\lambda) \alpha R^{2}-(1-\alpha) B} .
$$

The expected payoff difference $D$ has the following properties:

1. $D(x, \lambda)$ is continuous and strictly decreasing in $x$ for all $\lambda$.

2. There exist $\underline{x}>-\infty$ and $\bar{x}<+\infty$ such that for all $\lambda$ we have $D(x, \lambda)>0$ for $x<\underline{x}$ and $D(x, \lambda)<0$ for $x>\bar{x}$.

3. For $x \geq \underline{x}$, we have $D(x, \lambda)$ non-decreasing in $\lambda$.

Suppose the fundamental is $\theta$ and consider first the case that all other creditors withdraw for $x<k$ for some $k$. Then the proportion $\lambda$ of creditors who withdraw satisfies

$$
\lambda \geq \operatorname{Pr}[x \leq k \mid \theta]=F_{\varepsilon}\left(\frac{k-\theta}{\sigma}\right)
$$

Since $D(x, \lambda)$ is non-decreasing in $\lambda$ for $x \geq \underline{x}$, creditor $j$ 's expected payoff difference in this case is bounded from below:

$$
E\left[D\left(x_{j}, \lambda\right) \mid x_{j}, s_{-j}(x)=1 \forall x<k\right] \geq \Delta\left(x_{j}, k\right)
$$

where the payoff bound $\Delta(x, k)$ is defined as:

$$
\Delta(x, k)=\int_{0}^{1} D\left(x, F_{\varepsilon}\left(\frac{k-\theta}{\sigma}\right)\right) d \mathcal{F}(\theta \mid x)
$$


Similarly, consider second the case that all other creditors roll over for $x>k^{\prime}$ for some $k^{\prime}$, which implies $\lambda \leq \operatorname{Pr}\left[x \leq k^{\prime} \mid \theta\right]$. In this case, creditor $j$ 's expected payoff difference is bounded from above by $\Delta\left(x_{j}, k^{\prime}\right)$ :

$$
E\left[D\left(x_{j}, \lambda\right) \mid x_{j}, s_{-j}(x)=0 \forall x>k^{\prime}\right] \leq \Delta\left(x_{j}, k^{\prime}\right)
$$

Given these bounding properties, it is sufficient to use the payoff bound $\Delta(x, k)$ for the iterative elimination of strictly dominated strategies. The payoff bound $\Delta$ has the following properties:

1. $\Delta(x, k)>0$ for $x<\underline{x}$ and $\Delta(x, k)<0$ for $x>\bar{x}$ with the corresponding weak inequalities at the boundaries $\underline{x}$ and $\bar{x}$.

2. $\Delta(x, k)$ is continuous in $x$ and it is non-increasing in $x$ for $x \geq \underline{x}$.

3. $\Delta(x, k)$ may not be continuous in $k$ but it is non-decreasing in $k$ as long as $x$ satisfies $x \geq \underline{x}$.

Define $\underline{\kappa}_{0}=-\infty$ and $\bar{\kappa}_{0}=+\infty$ as well as $\underline{\kappa}_{n}$ and $\bar{\kappa}_{n}$ for $n \geq 1$ inductively by:

$$
\begin{aligned}
& \underline{\kappa}_{n}=\min \left\{x: \Delta\left(x, \underline{\kappa}_{n-1}\right)=0\right\} \\
& \bar{\kappa}_{n}=\max \left\{x: \Delta\left(x, \bar{\kappa}_{n-1}\right)=0\right\}
\end{aligned}
$$

Given the properties of $\Delta, \underline{\kappa}_{n}$ is a non-decreasing sequence with $\underline{\kappa}_{0}<\underline{x}=\underline{\kappa}_{1}$ and $\bar{x}$ as an upper bound. Similarly, $\bar{\kappa}_{n}$ is a non-increasing sequence with $\bar{\kappa}_{0}>\bar{x}=\bar{\kappa}_{1}$ and $\underline{x}$ as a lower bound.

Claim. A strategy $\mathbf{s}(x)$ survives $n$ rounds of iterative elimination of strictly dominated strategies if and only if it satisfies $\mathbf{s}(x)=1$ for $x<\underline{\kappa}_{n}$ and $\mathbf{s}(x)=0$ for $x>\bar{\kappa}_{n}$.

Proof. The claim is true for $n=1$ since a strategy survives one round of elimination if and only if $\mathbf{s}(x)=1$ for $x<\underline{x}=\underline{\kappa}_{1}$ and $\mathbf{s}(x)=0$ for $x>\bar{x}=\bar{\kappa}_{1}$. Suppose the claim is true for $n-1$. Then a strategy survives elimination of strictly dominated strategies in round $n$ if and only if it satisfies $\mathbf{s}(x)=1$ wherever $\Delta\left(x, \underline{\kappa}_{n-1}\right)>0$ and $\mathbf{s}(x)=0$ wherever $\Delta\left(x, \bar{\kappa}_{n-1}\right)<0$. By definition, $\underline{\kappa}_{n}$ and $\bar{\kappa}_{n}$ are the respective smallest and largest values of $x$ where these conditions are satisfied, so the claim is true for $n$. 
Since $\underline{\kappa}_{n}$ and $\bar{\kappa}_{n}$ are monotonic sequences on a bounded interval, we know that $\underline{\kappa}_{n} \rightarrow \underline{\kappa}$ and $\bar{\kappa}_{n} \rightarrow \bar{\kappa}$ as $n \rightarrow \infty$ for some $\underline{\kappa}$ and $\bar{\kappa}$ with $\Delta(\underline{\kappa}, \underline{\kappa})=\Delta(\bar{\kappa}, \bar{\kappa})=0$. It remains to show that there is a unique switching point $\hat{x}$ with $\Delta(\hat{x}, \hat{x})=0$.

Consider the uncertainty a creditor with signal $x$ faces about the fraction $\lambda$ of other creditors receiving a signal less than some $k$. For a fundamental $\theta$ the proportion of creditors with signal $x<k$ is given by $F_{\varepsilon}\left(\frac{k-\theta}{\sigma}\right)$ which is less than some $\lambda$ if and only if $\theta>k-\sigma F_{\varepsilon}^{-1}(\lambda)$. Given a signal $x$, the probability of this is:

$$
\begin{aligned}
\Gamma(\lambda \mid x, k) & =1-\mathcal{F}\left(k-\sigma F_{\varepsilon}^{-1}(\lambda) \mid x\right) \\
& =1-\frac{\int_{0}^{k-\sigma F_{\varepsilon}^{-1}(\lambda)} f(\theta) \frac{1}{\sigma} f_{\varepsilon}\left(\frac{x-\theta}{\sigma}\right) d \theta}{\int_{0}^{1} f(\theta) \frac{1}{\sigma} f_{\varepsilon}\left(\frac{x-\theta}{\sigma}\right) d \theta} \\
& =1-\frac{\int_{\frac{x-k}{\sigma}+F_{\varepsilon}^{-1}(\lambda)}^{\frac{x}{\sigma}} f(x-\sigma z) f_{\varepsilon}(z) d z}{\int_{\frac{x-1}{\sigma}}^{\frac{x}{\sigma}} f(x-\sigma z) f_{\varepsilon}(z) d z} \text { using } \quad z=\frac{x-\theta}{\sigma}
\end{aligned}
$$

Changing variables again:

$$
\Gamma(\lambda \mid x, x-\sigma \xi)=1-\frac{\int_{\xi+F_{\varepsilon}^{-1}(\lambda)}^{\frac{x}{\sigma}} f(x-\sigma z) f_{\varepsilon}(z) d z}{\int_{\frac{x-1}{\sigma}}^{\frac{x}{\sigma}} f(x-\sigma z) f_{\varepsilon}(z) d z} \quad \text { using } \quad \xi=\frac{x-k}{\sigma}
$$

As the signal noise $\sigma$ goes to 0 , the effect of the prior $f$ on $\Gamma$ disappears:

$$
\begin{aligned}
\lim _{\sigma \rightarrow 0} \Gamma(\lambda \mid x, x-\sigma \xi) & =1-\int_{\xi+F_{\varepsilon}^{-1}(\lambda)}^{\infty} f_{\varepsilon}(z) d z \\
& =F_{\varepsilon}\left(\xi+F_{\varepsilon}^{-1}(\lambda)\right)
\end{aligned}
$$

Finally, for a signal equal to the switching point, $x=k$ or $\xi=0$, the distribution $\Gamma$ becomes uniform on $[0,1]$ :

$$
\lim _{\sigma \rightarrow 0} \Gamma(\lambda \mid x, x)=\lambda
$$

Using $\Gamma$, we can express $\Delta$ as follows:

$$
\Delta(x, k)=\int_{0}^{1} D(x, \lambda) d \Gamma(\lambda \mid x, k)
$$


Using (11) we have that in the limit $\sigma \rightarrow 0$,

$$
\Delta(x, x)=\int_{0}^{1} D(x, \lambda) d \lambda
$$

and the properties of $D$ imply there is a unique $\hat{x}$ such that $\Delta(\hat{x}, \hat{x})=0$.

In the limit, the payoff difference $D$ becomes:

$$
D(x, \lambda)= \begin{cases}\int_{\underline{\ell}}^{\hat{\ell}(\lambda)} \delta d G(\ell)+\int_{\hat{\ell}(\lambda)}^{\bar{\ell}}\left(R-x R^{2}\right) d G(\ell) & \text { for } x \leq \bar{\theta} \\ R-R^{2} & \text { for } x>\bar{\theta}\end{cases}
$$

Note that the equilibrium switching point has to satisfy $\hat{x} \leq \bar{\theta}$ so we have

$$
\begin{aligned}
\Delta(\hat{x}, \hat{x}) & =\int_{0}^{1} D(\hat{x}, \lambda) d \lambda \\
& =\int_{0}^{1}\left(\int_{\underline{\ell}}^{\hat{\ell}(\lambda)} \delta d G(\ell)+\int_{\hat{\ell}(\lambda)}^{\bar{\ell}}\left(R-\hat{x} R^{2}\right) d G(\ell)\right) d \lambda
\end{aligned}
$$

Solving $\Delta(\hat{x}, \hat{x})=0$ for the switching point, we arrive at:

$$
\hat{x}=\frac{1}{R}+\frac{1}{R^{2}} \frac{\int_{0}^{1} \delta G(\hat{\ell}(\lambda)) d \lambda}{\int_{0}^{1}(1-G(\hat{\ell}(\lambda))) d \lambda}
$$

In equilibrium, for realizations of the fundamental $\theta \leq \hat{x}$ all creditors withdraw and the bank fails while for realizations $\theta>\hat{x}$, all creditors roll over and the bank survives. The bank's failure threshold in terms of the fundamental $\theta$ is therefore $\hat{\theta}=\hat{x}$.

Since all banks are symmetric ex-ante, I focus on competitive equilibria with symmetric choices of maturity structure $\alpha_{i}=\alpha_{i^{\prime}}$ for all banks $i, i^{\prime}$ at $t=0$. With symmetric $\alpha_{i}$ and $R_{i}$ for all $i$, equilibrium switching points at $t=1$ are symmetric, $\hat{x}_{i}=\hat{x}_{i^{\prime}}$ for all $i, i^{\prime}$. For a common, deterministic failure threshold across all banks the law of large numbers implies that the fraction of banks failing and therefore the mass of assets sold is $\phi=\operatorname{Pr}[\theta \leq \hat{\theta}]=F(\hat{\theta})$, so the liquidation value is $\ell(F(\hat{\theta}))$. In summary, in a symmetric competitive equilibrium, there is no uncertainty about $\ell$ (conditional on $s$ ) and the threshold in (12) simplifies to the expression in (1). 
Proof of Lemma 1. The two key equations are the indifference condition (IC) and the break-even constraint $(\mathrm{BC})$ :

$$
\begin{gathered}
\hat{\lambda}(\alpha, \ell)\left(\hat{\theta} R^{2}-R\right)=(1-\hat{\lambda}(\alpha, \ell)) \delta \\
F(\hat{\theta}) \ell+\int_{\hat{\theta}}^{1} \theta R^{2} d F(\theta)=1
\end{gathered}
$$

To show that the mapping between $\alpha$ and $\hat{\theta}$ is one-to-one, we first need to show that only one $\alpha$ implements each $\hat{\theta}$. This is straightforward since (IC) is linear in $\alpha$ and (BC) doesn't depend on $\alpha$ at all.

Next, we need to show that each $\alpha$ implements only one $\hat{\theta}$. Differentiating the left-hand side of (BC) with respect to $\hat{\theta}$ without substitution of $R$ we get:

$$
\left.2 R \frac{d R}{d \hat{\theta}}\right|_{(\mathrm{IC})} \int_{\hat{\theta}}^{1} \theta d F(\theta)-f(\hat{\theta})\left(\hat{\theta} R^{2}-\ell\right)
$$

Implicit differentiation of (IC) yields:

$$
\left.\frac{d R}{d \hat{\theta}}\right|_{(\mathrm{IC})}=\frac{-R^{2}\left(X-R^{2}\right)}{2 R\left(X-2 R^{2}\right) \hat{\theta}-\left(X-3 R^{2}+\left(\alpha \frac{X}{\ell}+2(1-\alpha) R\right) \delta\right)}
$$

The numerator is negative and, substituting in for $\hat{\theta}$, the denominator is positive if

$$
\begin{aligned}
\left(R^{3}-R X\right)^{2}>\delta[R( & \left(3 R^{2}-X\right)\left(\alpha R \frac{X}{\ell}+(1-\alpha) R^{2}\right) \\
& \left.+(1-\alpha) R^{3}\left(X-R^{2}\right)+2 R X\left(X-2 R^{2}\right)\right],
\end{aligned}
$$

which is guaranteed for sufficiently small $\delta$. Again using (IC) we get:

$$
\hat{\theta} R^{2}-\ell=R-\ell+\delta \frac{R\left(\alpha \frac{X}{\ell}+(1-\alpha) R\right)-X}{X-R^{2}},
$$

which is guaranteed to be positive for sufficiently small $\delta$. The fact that $d R /\left.d \hat{\theta}\right|_{(\mathrm{IC})}<0$ and $\hat{\theta} R^{2}-\ell>0$ implies that the expression (13) is strictly negative. Therefore each $\alpha$ implements only one $\hat{\theta}$ and we can conclude that the mapping between $\alpha$ and $\hat{\theta}$ is one-to-one. 
Finally we need to show that $d \hat{\theta} / d \alpha>0$. Implicit differentiation of (BC) yields:

$$
\frac{d \hat{\theta}}{d \alpha}=-\frac{\left.2 R \frac{d R}{d \alpha}\right|_{(\mathrm{IC})} \int_{\hat{\theta}}^{1} \theta d F(\theta)}{\left.2 R \frac{d R}{d \hat{\theta}}\right|_{(\mathrm{IC})} \int_{\hat{\theta}}^{1} \theta d F(\theta)-f(\hat{\theta})\left(R^{2} \hat{\theta}-\ell\right)}
$$

The denominator is equal to expression (13) which we have already established is negative. Implicit differentiation of (IC) yields

$$
\left.\frac{d R}{d \alpha}\right|_{(\mathrm{IC})}=\frac{\left(\frac{X}{\ell}-R\right) R \delta}{2 R\left(X-2 R^{2}\right) \hat{\theta}-\left(X-3 R^{2}+\left(\alpha \frac{X}{\ell}+2(1-\alpha) R\right) \delta\right)},
$$

which is positive since the denominator is the same as in $d R /\left.d \hat{\theta}\right|_{(\mathrm{IC})}$. Therefore the nominator in (14) is positive and we can conclude that $d \hat{\theta} / d \alpha>0$.

Proof of Proposition 2. Given Lemma 1 this result is straightforward. The bank solves the following problem:

$$
\max _{\alpha}\left\{F(\hat{\theta}(\alpha)) \ell+\int_{\hat{\theta}(\alpha)}^{1} \theta X d F(\theta)-1\right\}
$$

The first order condition to this problem is:

$$
f(\hat{\theta}(\alpha)) \hat{\theta}^{\prime}(\alpha)(\ell-\hat{\theta}(\alpha) X)=0
$$

With the properties of $\hat{\theta}(\alpha)$ established in Lemma 1, this implies the efficient rollover threshold $\hat{\theta}\left(\alpha^{*}\right)=\ell / X$ which is implemented by an optimal maturity structure $\alpha^{*}=$ $\hat{\theta}^{-1}(\ell / X)$.

Proof of Proposition 3. The bank solves the following problem:

$$
\begin{aligned}
\max _{\alpha}\{p & \left(F_{H}\left(\hat{\theta}_{H}(\alpha)\right) \ell_{H}+\int_{\hat{\theta}_{H}(\alpha)}^{1} \theta X d F_{H}(\theta)\right) \\
& \left.+(1-p)\left(F_{L}\left(\hat{\theta}_{L}(\alpha)\right) \ell_{L}+\int_{\hat{\theta}_{L}(\alpha)}^{1} \theta X d F_{L}(\theta)\right)-1\right\}
\end{aligned}
$$


The first order condition to this problem is:

$$
\begin{aligned}
& p f_{H}\left(\hat{\theta}_{H}(\alpha)\right) \hat{\theta}_{H}^{\prime}(\alpha)\left(\ell_{H}-\hat{\theta}_{H}(\alpha) X\right) \\
& \quad+(1-p) f_{L}\left(\hat{\theta}_{L}(\alpha)\right) \hat{\theta}_{L}^{\prime}(\alpha)\left(\ell_{L}-\hat{\theta}_{L}(\alpha) X\right)=0
\end{aligned}
$$

Since $\ell_{H}>\ell_{L}$ and $\hat{\theta}_{H}(\alpha)<\hat{\theta}_{L}(\alpha)$ the first order condition implies that for the optimal maturity structure $\alpha^{\dagger}$ we have:

$$
\ell_{H}-\hat{\theta}_{H}\left(\alpha^{\dagger}\right) X>0 \quad \text { and } \quad \ell_{L}-\hat{\theta}_{L}\left(\alpha^{\dagger}\right) X<0
$$

In state $H$, projects are inefficiently continued for $\theta \in\left(\hat{\theta}_{H}\left(\alpha^{\dagger}\right), \frac{\ell_{H}}{X}\right)$, while in state $L$, projects are inefficiently liquidated whenever $\theta \in\left(\frac{\ell_{L}}{X}, \hat{\theta}_{L}\left(\alpha^{\dagger}\right)\right)$.

Proof of Proposition 4. The first-best allocation equates the marginal product of assets in alternative use with the expected payoff of the marginal asset in the banking system, $Y^{\prime}(\phi)=\hat{\theta} X$. With $Y^{\prime}(\phi)=\ell$ and $\hat{\theta}\left(\alpha^{*}\right)=\ell / X$, the competitive equilibrium achieves this allocation.

Proof of Lemma 2. By first order stochastic dominance, we have $F_{H}(\theta)<F_{L}(\theta)$ for any $\theta \in(0,1)$ so the first-best allocation in (8) satisfies $\phi_{H}^{\mathrm{FB}}<\phi_{L}^{\mathrm{FB}}$ and therefore $\ell\left(\phi_{H}^{\mathrm{FB}}\right)>\ell\left(\phi_{L}^{\mathrm{FB}}\right)$.

Proof of Proposition 5. Proposition 3 implies that in the competitive equilibrium we have:

$$
\begin{aligned}
\hat{\theta}_{H}\left(\alpha^{\dagger}\left(\Phi^{\mathrm{CE}}\right), \Phi^{\mathrm{CE}}\right) & <\frac{\ell\left(\phi_{H}^{\mathrm{CE}}\right)}{X} \\
\text { and } \hat{\theta}_{L}\left(\alpha^{\dagger}\left(\Phi^{\mathrm{CE}}\right), \Phi^{\mathrm{CE}}\right) & >\frac{\ell\left(\phi_{L}^{\mathrm{CE}}\right)}{X}
\end{aligned}
$$

These inequalities imply that:

$$
\begin{array}{r}
F_{H}\left(\hat{\theta}_{H}\left(\alpha^{\dagger}\left(\Phi^{\mathrm{CE}}\right), \Phi^{\mathrm{CE}}\right)\right)<F_{H}\left(\frac{\ell\left(\phi_{H}^{\mathrm{CE}}\right)}{X}\right) \\
\text { and } F_{L}\left(\hat{\theta}_{L}\left(\alpha^{\dagger}\left(\Phi^{\mathrm{CE}}\right), \Phi^{\mathrm{CE}}\right)\right)>F_{L}\left(\frac{\ell\left(\phi_{L}^{\mathrm{CE}}\right)}{X}\right)
\end{array}
$$


Given the implicit definitions of $\Phi^{\mathrm{CE}}$ in (7) and of $\Phi^{\mathrm{FB}}$ in (8) as well as the fact that $F_{s}(\ell(\phi) / X)$ is decreasing in $\phi$ for both $s=H, L$ we can conclude from the inequalities (16) and (17) that $\phi_{H}^{\mathrm{CE}}<\phi_{H}^{\mathrm{FB}}$ and $\phi_{L}^{\mathrm{CE}}>\phi_{L}^{\mathrm{FB}}$, respectively. These inequalities, in turn, imply that $\ell\left(\phi_{H}^{\mathrm{CE}}\right)>\ell\left(\phi_{H}^{\mathrm{FB}}\right)$ and $\ell\left(\phi_{L}^{\mathrm{CE}}\right)<\ell\left(\phi_{L}^{\mathrm{FB}}\right)$.

Proof of Proposition 6. The constrained social planner's objective function is the following:

$$
\sum_{s=H, L} p_{s}[\underbrace{Y\left(F_{s}\left(\hat{\theta}_{s}\right)\right)}_{\text {alternative use }}+\underbrace{\int_{\hat{\theta}_{s}}^{1} \theta X d F_{s}(\theta)}_{\text {bank projects }}]-1
$$

The first term in square brackets is the output of the secondary sector with production function $Y(\phi)$ which uses all assets liquidated by the banking sector in $t=1$, i.e. the projects of all banks with realizations $\theta_{i}<\hat{\theta}_{s}$. The second term of the objective function is the output of the projects remaining in the banking sector, i.e. the projects of all banks with realizations $\theta_{i}>\hat{\theta}_{s}$.

The social planner's first-order condition with respect to $\alpha$ is given by:

$$
\sum_{s=H, L} p_{s} f_{s}\left(\hat{\theta}_{s}\right) \frac{d \hat{\theta}_{s}}{d \alpha}\left(Y^{\prime}\left(F_{s}\left(\hat{\theta}_{s}\right)\right)-\hat{\theta}_{s} X\right)=0
$$

With $\phi_{s}=F_{s}\left(\hat{\theta}_{s}\right)$ and $Y^{\prime}\left(\phi_{s}\right)=\ell_{s}$, this simplifies to:

$$
p f_{H}\left(\hat{\theta}_{H}\right) \frac{d \hat{\theta}_{H}}{d \alpha}\left(\ell_{H}-\hat{\theta}_{H} X\right)+(1-p) f_{L}\left(\hat{\theta}_{L}\right) \frac{d \hat{\theta}_{L}}{d \alpha}\left(\ell_{L}-\hat{\theta}_{L} X\right)=0
$$

While this first-order condition looks very similar to the first-order condition (15) for an individual bank, there is a subtle difference since the threshold $\hat{\theta}_{s}$ depends on both $\alpha$ and $\phi_{s}$ (through $\ell_{s}$ ). While an individual bank choosing $\alpha$ only takes into account the direct effect of $\alpha$, the social planner also takes into account the indirect effect of $\alpha$ on $\phi_{s}$ :

$$
\begin{aligned}
\text { Individual bank: } & \frac{d \hat{\theta}_{s}}{d \alpha}=\frac{\partial \hat{\theta}_{s}}{\partial \alpha} \\
\text { Social planner: } & \frac{d \hat{\theta}_{s}}{d \alpha}=\frac{\partial \hat{\theta}_{s}}{\partial \alpha}+\frac{\partial \hat{\theta}_{s}}{\partial \phi_{s}} \frac{d \phi_{s}}{d \alpha}
\end{aligned}
$$


We have $\phi_{s}$ determined by a fixed point

$$
\phi_{s}=F_{s}\left(\hat{\theta}_{s}\left(\alpha, \phi_{s}\right)\right)
$$

so implicit differentiation yields the effect of $\alpha$ on $\phi_{s}$ :

$$
\frac{d \phi_{s}}{d \alpha}=\frac{f_{s}\left(\hat{\theta}_{s}\right) \frac{\partial \hat{\theta}_{s}}{\partial \alpha}}{1-f_{s}\left(\hat{\theta}_{s}\right) \frac{\partial \hat{\theta}_{s}}{\partial \phi_{s}}}
$$

The effect of $\alpha$ on $\hat{\theta}_{s}$ from the social planner's point of view is therefore

$$
\frac{d \hat{\theta}_{s}}{d \alpha}=\frac{\partial \hat{\theta}_{s}}{\partial \alpha}+\frac{\partial \hat{\theta}_{s}}{\partial \phi_{s}} \frac{f_{s}\left(\hat{\theta}_{s}\right) \frac{\partial \hat{\theta}_{s}}{\partial \alpha}}{1-f_{s}\left(\hat{\theta}_{s}\right) \frac{\partial \hat{\theta}_{s}}{\partial \phi_{s}}}=\frac{1}{1-f_{s}\left(\hat{\theta}_{s}\right) \frac{\partial \hat{\theta}_{s}}{\partial \phi_{s}}} \frac{\partial \hat{\theta}_{s}}{\partial \alpha}
$$

Evaluating the derivative of the social planner's objective function at the private optimum yields:

$$
\begin{aligned}
& \sum_{s=H, L} p_{s} f_{s}\left(\hat{\theta}_{s}\right) \frac{1}{1-f_{s}\left(\hat{\theta}_{s}\right) \frac{\partial \hat{\theta}_{s}}{\partial \phi_{s}}} \frac{\partial \hat{\theta}_{s}}{\partial \alpha}\left(\ell_{s}-\hat{\theta}_{s} X\right) \\
& =\left(\frac{1}{1-f_{H}\left(\hat{\theta}_{H}\right) \frac{\partial \hat{\theta}_{H}}{\partial \phi_{H}}}-\frac{1}{1-f_{L}\left(\hat{\theta}_{L}\right) \frac{\partial \hat{\theta}_{L}}{\partial \phi_{L}}}\right) p f_{H}\left(\hat{\theta}_{H}\right) \frac{\partial \hat{\theta}_{H}}{\partial \alpha}\left(\ell_{H}-\hat{\theta}_{H} X\right)
\end{aligned}
$$

The social planner chooses higher $\alpha$ than in the competitive equilibrium if and only if (19) is positive which results in

$$
\alpha^{\mathrm{SP}} \lessgtr \alpha^{\mathrm{CE}} \Leftrightarrow \frac{f_{H}\left(\hat{\theta}_{H}^{\mathrm{CE}}\right)}{f_{L}\left(\hat{\theta}_{L}^{\mathrm{CE}}\right)} \lessgtr \frac{\ell^{\prime}\left(\phi_{L}^{\mathrm{CE}}\right)}{\ell^{\prime}\left(\phi_{H}^{\mathrm{CE}}\right)},
$$

as desired.

Proof of Proposition 7. The only effect of crisis bonds on the global game among short-term creditors is through the failure threshold for $\ell$ which now depends on 
whether the bonds are triggered or not:

$$
\begin{aligned}
\text { Not triggered: } & \hat{\ell}_{0}(\lambda) \equiv \frac{\alpha \lambda R X}{X-(1-\lambda) \alpha R^{2}-\gamma C-(1-\alpha-\gamma) B} \\
\text { Triggered: } & \hat{\ell}_{1}(\lambda) \equiv \frac{\alpha \lambda R X}{X-(1-\lambda) \alpha R^{2}-(1-\alpha-\gamma) B}
\end{aligned}
$$

Since the sign of the effect of $\lambda$ on $\hat{\ell}$ is unaffected by the crisis bonds, the properties of the expected payoff difference $D(x, \lambda)$ are also unaffected and the reasoning in the proof of Proposition 1 is unchanged. Without uncertainty about $\ell$ and accounting for the difference between $\hat{\ell}_{0}(\lambda)$ and $\hat{\ell}_{1}(\lambda)$, the switching point in (12) simplifies to the expressions in the proposition.

Proof of Lemma 3. First, note that since only $\hat{\lambda}_{0}$ depends on $C$, only the expression for $\hat{\theta}_{H}$ in (9) is relevant. We have

$$
\frac{d \hat{\lambda}_{0}}{d \gamma}=-\frac{C-B}{\alpha R\left(\frac{X}{\ell}-R\right)} .
$$

Because crisis bond holders are paid only in state $H$ while regular long-term creditors are paid in both states, we have $C>B$. Therefore, $d \hat{\lambda}_{0} / d \gamma<0$ analogous to $d \hat{\lambda}_{0} / d \alpha<0$ and the reasoning of Lemma 1 carries over to the mapping between $\hat{\theta}_{H}$ and $\gamma$ and yields $d \hat{\theta}_{H} / d \gamma>0$. We further have

$$
\frac{d \hat{\lambda}_{1}}{d \gamma}=\frac{B}{\alpha R\left(\frac{X}{\ell}-R\right)}>0
$$

and therefore $d \hat{\theta}_{L} / d \gamma<0$.

Proof of Proposition 8. The introduction of crisis bond holders slightly changes the break-even constraints for short-term and long-term creditors. Conditional on the bank being liquidated in $t=1$, they receive $\ell_{H}$ in state $H$, where all creditors share the liquidation proceeds, but $\ell_{L} /(1-\gamma)$ in state $L$, where the crisis bond holders don't have a claim. Accounting for this change, the crisis bond holders don't affect the fact 
that the bank maximizes economic surplus:

$$
\begin{aligned}
\max _{\alpha, \gamma}\left\{p\left(F_{H}\left(\hat{\theta}_{H}(\alpha, \gamma)\right) \ell_{H}+\int_{\hat{\theta}_{H}(\alpha, \gamma)}^{1} \theta X d F_{H}(\theta)\right)\right. \\
\left.\quad+(1-p)\left(F_{L}\left(\hat{\theta}_{L}(\alpha, \gamma)\right) \ell_{L}+\int_{\hat{\theta}_{L}(\alpha, \gamma)}^{1} \theta X d F_{L}(\theta)\right)-1\right\}
\end{aligned}
$$

The bank's first oder condition for $\alpha$ is

$$
\begin{aligned}
& p f_{H}\left(\hat{\theta}_{H}(\alpha, \gamma)\right) \frac{\partial}{\partial \alpha} \hat{\theta}_{H}(\alpha, \gamma)\left(\ell_{H}-\hat{\theta}_{H}(\alpha, \gamma) X\right) \\
& \quad+(1-p) f_{L}\left(\hat{\theta}_{L}(\alpha, \gamma)\right) \frac{\partial}{\partial \alpha} \hat{\theta}_{L}(\alpha, \gamma)\left(\ell_{L}-\hat{\theta}_{L}(\alpha, \gamma) X\right)=0
\end{aligned}
$$

and for $\gamma$ :

$$
\begin{aligned}
& p f_{H}\left(\hat{\theta}_{H}(\alpha, \gamma)\right) \frac{\partial}{\partial \gamma} \hat{\theta}_{H}(\alpha, \gamma)\left(\ell_{H}-\hat{\theta}_{H}(\alpha, \gamma) X\right) \\
& \quad+(1-p) f_{L}\left(\hat{\theta}_{L}(\alpha, \gamma)\right) \frac{\partial}{\partial \gamma} \hat{\theta}_{L}(\alpha, \gamma)\left(\ell_{L}-\hat{\theta}_{L}(\alpha, \gamma) X\right)=0
\end{aligned}
$$

For an interior solution, the bank chooses $\alpha$ and $\gamma$ such that $\hat{\theta}_{H}\left(\alpha^{\star}, \gamma^{\star}\right)=\ell_{H} / X$ and $\hat{\theta}_{L}\left(\alpha^{\star}, \gamma^{\star}\right)=\ell_{L} / X$ and both first order conditions are satisfied. Analogous to Proposition 4 , these choices implement the first-best allocation. 


\section{References}

Acharya, V. V., D. Gale, and T. Yorulmazer (2011). Rollover risk and market freezes. Journal of Finance 66(4), 1177-1209.

Admati, A. R., P. M. DeMarzo, M. F. Hellwig, and P. Pfleiderer (2013). Fallacies, irrelevant facts, and myths in the discussion of capital regulation: Why bank equity is not expensive. Working Paper, Stanford University.

Adrian, T. and M. K. Brunnermeier (2016). CoVaR. American Economic Review $106(7), 1705-1741$.

Adrian, T., P. Colla, and H. S. Shin (2013). Which financial frictions? Parsing the evidence from the financial crisis of 2007-9. In D. Acemoglu, J. Parker, and M. Woodford (Eds.), NBER Macroeconomics Annual, Volume 27, pp. 159-214.

Adrian, T. and H. S. Shin (2010). The changing nature of financial intermediation and the financial crisis of 2007-2009. Annual Review of Economics 2(1), 603-618.

Aghion, P. and P. Bolton (1989). The financial structure of the firm and the problem of control. European Economic Review 33(2-3), 286-293.

Ahnert, T. (2015). Rollover risk, liquidity and macroprudential regulation. Journal of Money, Credit and Banking (forthcoming).

Allen, F. and D. Gale (1994). Limited market participation and volatility of asset prices. American Economic Review 84(4), 933-955.

Allen, F. and D. Gale (1998). Optimal financial crises. Journal of Finance 53(4), $1245-1284$.

Angeletos, G.-M., C. Hellwig, and A. Pavan (2007). Dynamic global games of regime change: Learning, multiplicity, and the timing of attacks. Econometrica 75(3), 711756.

Bord, V. M. and J. A. C. Santos (2014). Banks' liquidity and cost of liquidity to corporations. Journal of Money, Credit and Banking 46(s1), 1538-4616. 
Brunnermeier, M. K. (2009). Deciphering the liquidity and credit crunch 2007-2008. Journal of Economic Perspectives 23(1), 77-100.

Bryant, J. (1980). A model of reserves, bank runs, and deposit insurance. Journal of Banking and Finance 4(4), 335-344.

Calomiris, C. W. and C. M. Kahn (1991). The role of demandable debt in structuring optimal banking arrangements. American Economic Review 81(3), 497-513.

Carey, M., A. K. Kashyap, R. Rajan, and R. M. Stulz (2012). Market institutions, financial market risks, and the financial crisis. Journal of Financial Economics 104(3), 421-424.

Carlsson, H. and E. van Damme (1993a). Equilibrium selection in stag hunt games. In K. Binmore, A. Kirman, and P. Tani (Eds.), Frontiers of Game Theory. MIT Press.

Carlsson, H. and E. van Damme (1993b). Global games and equilibrium selection. Econometrica 61(5), 989-1018.

Cheng, I.-H. and K. W. Milbradt (2012). The hazards of debt: Rollover freezes, incentives, and bailouts. Review of Financial Studies 25(4), 1070-1110.

Cole, H. L. and T. J. Kehoe (2000). Self-fulfilling debt crises. Review of Economic Studies 67(1), 91-116.

Copeland, A., A. Martin, and M. Walker (2014). Repo runs: Evidence from the tri-party repo market. Journal of Finance 69(6), 2343-2380.

Covitz, D., N. Liang, and G. A. Suarez (2013). The evolution of a financial crisis: Collapse of the asset-backed commercial paper market. Journal of Finance 68(3), 815-848.

Dang, T. V., G. B. Gorton, and B. Holmström (2012). Ignorance, debt and financial crises. Working Paper, Yale University.

DeMarzo, P. M. and D. Duffie (1999). A liquidity-based model of security design. Econometrica 67(1), 65-99. 
Diamond, D. W. and P. H. Dybvig (1983). Bank runs, deposit insurance, and liquidity. Journal of Political Economy 91(3), 401-419.

Diamond, D. W. and R. G. Rajan (2000). A theory of bank capital. Journal of Finance 55(6), 2431-2465.

Diamond, D. W. and R. G. Rajan (2001). Liquidity risk, liquidity creation, and financial fragility: A theory of banking. Journal of Political Economy 109(2), 287-327.

Dávila, E. (2015). Dissecting fire sales externalities. Working Paper, New York University.

Geanakoplos, J. (2010). The leverage cycle. In NBER Macroeconomics Annual 2009, Volume 24, pp. 1-65. University of Chicago Press.

Goldstein, I. (2013). Empirical literature on financial crises: Fundamentals vs. panic. In G. Caprio (Ed.), The Evidence and Impact of Financial Globalization, Chapter 36, pp. 523-534. Elsevier.

Goldstein, I. and A. Pauzner (2005). Demand-deposit contracts and the probability of bank runs. Journal of Finance 60(3), 1293-1327.

Gorton, G. B. (2008). The panic of 2007. In Maintaining Stability in a Changing Financial System, Economic Policy Symposium. Federal Reserve Bank of Kansas City.

Gorton, G. B. and A. Metrick (2012). Securitized banking and the run on repo. Journal of Financial Economics 104(3), 425-451.

He, Z., I. G. Khang, and A. Krishnamurthy (2010). Balance sheet adjustments during the 2008 crisis. IMF Economic Review 58(1), 118-156.

He, Z. and A. Krishnamurthy (2012). A model of capital and crises. Review of Economic Studies $79(2), 735-777$.

He, Z. and A. Krishnamurthy (2013). Intermediary asset pricing. American Economic Review 103(2), 732-770. 
He, Z. and W. Xiong (2012). Dynamic debt runs. Review of Financial Studies 25(6), 1799-1843.

Innes, R. D. (1990). Limited liability and incentive contracting with ex-ante action choices. Journal of Economic Theory 52(1), 45-67.

Ivashina, V. and D. Scharfstein (2010). Bank lending during the financial crisis of 2008. Journal of Financial Economics 97(3), 319-338.

Jensen, M. C. and W. H. Meckling (1976). Theory of the firm: Managerial behavior, agency costs and ownership structure. Journal of Financial Economics 3(4), 305360.

Kacperczyk, M. and P. Schnabl (2010). When safe proved risky: Commercial paper during the financial crisis of 2007-2009. Journal of Economic Perspectives 24(1), $29-50$.

Kashyap, A. K., R. G. Rajan, and J. C. Stein (2008). Rethinking capital regulation. In Maintaining Stability in a Changing Financial System, Economic Policy Symposium. Federal Reserve Bank of Kansas City.

Kiyotaki, N. and J. Moore (1997). Credit cycles. Journal of Political Economy 105(2), 211-248.

Kurlat, P. (2010). Optimal financial fragility. Working Paper, Stanford University.

Leland, H. E. and K. B. Toft (1996). Optimal capital structure, endogenous bankruptcy, and the term structure of credit spreads. Journal of Finance 51(3), 987-1019.

Lorenzoni, G. (2008). Inefficient credit booms. Review of Economic Studies 75(3), 809-833.

Morris, S. and H. S. Shin (2003). Global games: Theory and applications. In M. Dewatripont, L. P. Hansen, and S. J. Turnovsky (Eds.), Advances in Economics and Econometrics (Proceedings of the Eighth World Congress of the Econometric Society). Cambridge University Press.

Morris, S. and H. S. Shin (2004). Coordination risk and the price of debt. European Economic Review 48(1), 133-153. 
Morris, S. and H. S. Shin (2010). Illiquidity component of credit risk. Working Paper, Princeton University.

Rajan, R. G. (1992). Insiders and outsiders: The choice between informed and arm'slength debt. Journal of Finance 47(4), 1367-1400.

Rochet, J.-C. and X. Vives (2004). Coordination failures and the lender of last resort: Was bagehot right after all? Journal of the European Economic Association 2(6), $1116-1147$.

Sandleris, G. and M. L. J. Wright (2014). The costs of financial crises: Resource misallocation, productivity and welfare in the 2001 Argentine crisis. Scandinavian Journal of Economics 116(1), 87-127.

Shleifer, A. and R. W. Vishny (1992). Liquidation values and debt capacity: A market equilibrium approach. Journal of Finance 47(4), 1343-1366.

Stein, J. C. (2012). Monetary policy as financial-stability regulation. Quarterly Journal of Economics 127(1), 57-95.

Szkup, M. (2013). Optimal debt maturity structure, rollover risk and strategic uncertainty. Working Paper. 